Review Article

\title{
Multidisciplinary Design Optimization of Aerial Vehicles: A Review of Recent Advancements
}

\author{
Athanasios Papageorgiou (D, Mehdi Tarkian, Kristian Amadori, and Johan Ölvander \\ Department of Management and Engineering, Linköping University, Linköping 58183, Sweden
}

Correspondence should be addressed to Athanasios Papageorgiou; athanasios.papageorgiou@liu.se

Received 1 February 2018; Accepted 6 May 2018; Published 23 May 2018

Academic Editor: Kenneth M. Sobel

Copyright (c) 2018 Athanasios Papageorgiou et al. This is an open access article distributed under the Creative Commons Attribution License, which permits unrestricted use, distribution, and reproduction in any medium, provided the original work is properly cited.

\begin{abstract}
The aim of this paper is to present the most common practices in multidisciplinary design optimization (MDO) of aerial vehicles over the past decade. The literature sample is identified through established internet search engines, and a stringent review methodology is implemented in order to ensure the selection of the most relevant sources. In this work, the primary emphasis is on the assessment of the state-of-the-art framework development strategies, while at a secondary level, the objective is to identify the possible improvement directions by evaluating the research trends and gaps. As an additional contribution, statistical studies are also provided, and it is shown how MDO of aerial vehicles has evolved in terms of problem formulation, disciplinary modeling, analysis capabilities, tool implementation, and general applicability. Given this foundation as well as the results of the review, this work concludes by presenting a roadmap for guiding academia and industry in respect to the application of MDO on aerial vehicles. Overall, the roadmap together with the literature review is not only expected to serve as a guide for newcomers into the MDO field but also as an elementary basis which will allow researchers to conduct additional studies in this important and constantly evolving area of design.
\end{abstract}

\section{Introduction}

One of the most critical factors that can influence the economic success of any organization is, and has always been, its ability to develop successful products. This logic holds true in the majority of complex engineering products, while at the same time, it can be argued that in recent years it has also become an aspect of utmost importance in the development process of aerial vehicles. Having a superior aircraft design is valued more than ever before by aerospace manufacturers, and as such, it has been identified as one of the key elements that can secure a strategic advantage over the competition and subsequently create the necessary foundation for future growth. To no surprise, better technology integration, faster development times, higher quality, and lower costs have all become increasingly vital concepts, and as a direct consequence, they should now more than ever have a crucial role within the core activities and functions of every contemporary product development process.
Multidisciplinary design optimization (MDO) is a field of engineering that has the potential to support the decisionmaking process and subsequently improve the development process of complex engineering products. Since the first review of Sobieszczanski-Sobieski and Haftka in 1996 [1], the research on MDO has been constantly expanding, and nowadays, it is possible to take advantage of advanced integration tools [2], enhanced analysis capabilities [3], efficient computing methods [4], sophisticated decomposition architectures [5], and improved uncertainty propagation techniques [6]. At the same time, the integration of MDO into the organizational functions has also been investigated [7], and to this date, there has been a number of studies regarding not only its role within the product development process [8] but also the challenges and roadblocks for its successful implementation [9].

An area of product development that has been traditionally benefited from the use of MDO is that of aerial vehicle design. Over the years, MDO has been applied in many case 
studies of aircraft design and overall, it has shown very promising results in both the initial (conceptual) and the later (detailed) phases of the development process [10]. In most cases, the disciplines which are taken into account aim to primarily capture the flying performance (e.g., aerodynamics, weight, and propulsion); while depending on the design requirements, a set of additional computational models may also be considered. Accordingly, simple software tools are preferred when the design space is known and high fidelity is not imperative, whereas advanced analysis codes can be used when unconventional configurations have to be explored or when a higher level of precision is required. On the whole, the possibilities of MDO in aerial vehicle design are continuously being enhanced, and at the moment, there are numerous case studies which focus on the improvement of the existing methods and the gradual implementation of entirely new features [11].

In light of the above, the primary objective of this review is to summarize the state of the art in MDO for aerial vehicle design, and subsequently to allow for further discussions regarding the possibilities for future developments. More specifically, this paper provides a comprehensive assessment of the research activities in the field over the last decade, and furthermore, it points out the current research trends as well as potential gaps in the existing literature. To support the analysis of the findings and help identify the possible directions for improvements, this work also provides statistical studies regarding the evolution of $\mathrm{MDO}$, and presents a collective classification of the common practices in problem formulation, disciplinary modeling, analysis capabilities, tool implementation, and general applicability. Having established the above foundation, this study concludes with the proposal of an appropriate roadmap for implementing MDO in the design of aerial vehicles, directions on how to use the roadmap, and lastly, with suggestions on how this roadmap can be further enhanced. Overall, the aim of this work is to serve as a guide for newcomers into the field, but more importantly, as a basic "building block" which will enable both the academia and the industry to conduct additional studies in this active and dynamically changing research field.

\section{Review Methodology}

The papers which are discussed in this work were identified through the use of a review methodology which was developed specifically for this case study in order to tackle the vast number of MDO publications and make sure that all the relevant publications have been considered (see Figure 1). First, the proposed methodology starts with the implementation of a set of "selection" activities until a sample of manageable size can be generated (selection rounds $1-4$ reduce the initially identified 467 papers down to 70). Once the essential papers have been collected, a more in-depth review begins by using a set of explicit conceptual criteria (review phase 1). At the end of this first review phase, the main research areas which will be later used to cluster the papers are established, and the references of the selected publications are assessed so that the most relevant and frequently cited sources can be brought forward. In this study, the process of evaluating the references resulted in the addition of 35 new papers, and the primary aim herein was to identify potentially important case studies that might have been neglected by the mechanisms of the search engine or missing entirely from the online server database. Finally, the aforementioned "snowballed" papers together with the rest of the selected literature are reviewed for a second time (review phase 2), and the results are organized in chapters in order to give a structured overview of the current state of the art and the research gaps.

In this literature study, the search was primarily conducted through established internet search engines like Scopus and Google Scholar due to their ease of use, accessibility, and extensive database. This approach has the main advantage of being open to all researchers regardless of their experience and connections in the field, but the main limitation is that in many instances, the artificial intelligence of the aforementioned engines may not be able to capture the true needs and intentions of the user. To tackle this problem, a set of representative keywords and keystrings were initially implemented, and thereafter, it was complemented by a number of search limitations in order to filter the results and reduce the sample size (see Table 1). Here, the three types of contribution which were sought after in the papers were the description of a direct MDO application in an aircraft case study; the development of a methodology for more efficient MDO implementation; and lastly, the review of either the practical uses or the theoretical research advancements in the MDO field. In total, the complete literature sample that was reviewed in this work consisted of 105 case studies which correspond to 43 journal articles and 62 conference papers [12-116], while in addition to this, 25 publications were also included as supporting literature in order to provide general information about the key MDO research topics [01-11] and the commonly used computational tools [117-130].

Overall, the present paper is divided in five primary sections with the introduction and the review methodology being the first two (see Figure 2). The next section in line is the presentation of the state of the art in MDO of aerial vehicles where the findings of the review have been organized in 8 main chapters (3.1 to 3.8): The principle here is that each chapter groups together topics that pertain to a specific area of the MDO process so that it can give a complete overview of the background and trends. At the end, the paper presents a discussion section that builds on the results in order to address several key points and sums up with a conclusion section that includes an outline of the most important contributions.

\section{State of the Art}

3.1. Problem Formulation. One of the most essential steps before carrying out a MDO study for an aerial vehicle is to be able to properly formulate an appropriate optimization problem that can adequately express the mission and the requirements of each design [10]. In general, this is typically achieved not only by selecting a suitable set of objectives which can provide indicative metrics regarding the desired 


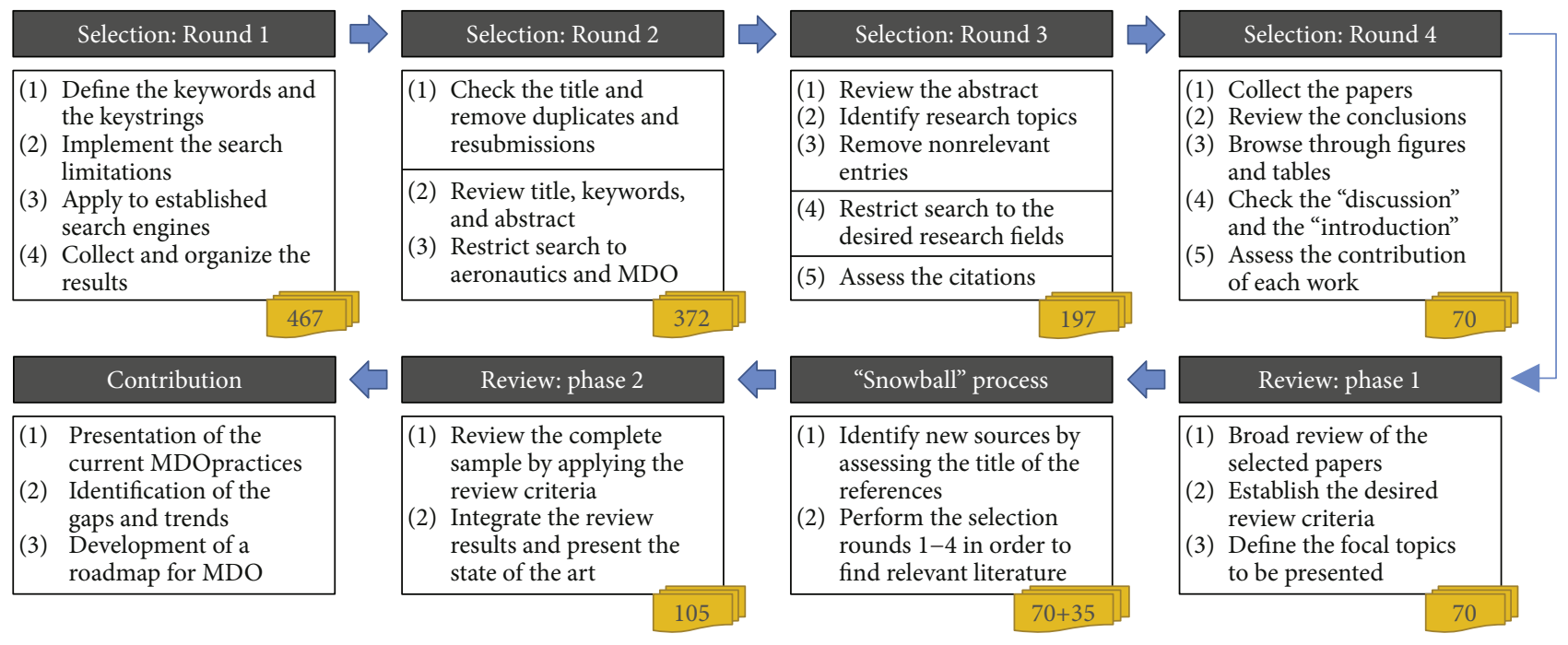

Figure 1: The review methodology.

TABLE 1: The keywords, keystrings, and search criteria used in the review process.

\begin{tabular}{|c|c|}
\hline Search fields & Title, abstract, and keywords \\
\hline $\begin{array}{l}\text { Keywords and } \\
\text { keystrings }\end{array}$ & $\begin{array}{l}\text { ["multidisciplinary optimization" or "multi-disciplinary optimization" or "multidisciplinary design optimization" or } \\
\text { "multi-disciplinary design optimization" or "MDO"] and ["aircraft" or "aerial vehicle" or "jet" or "aviation" or } \\
\text { "UAV"] }\end{array}$ \\
\hline Time span & January of 2006-December of 2016 \\
\hline Source type & Conference proceedings, journal articles \\
\hline
\end{tabular}
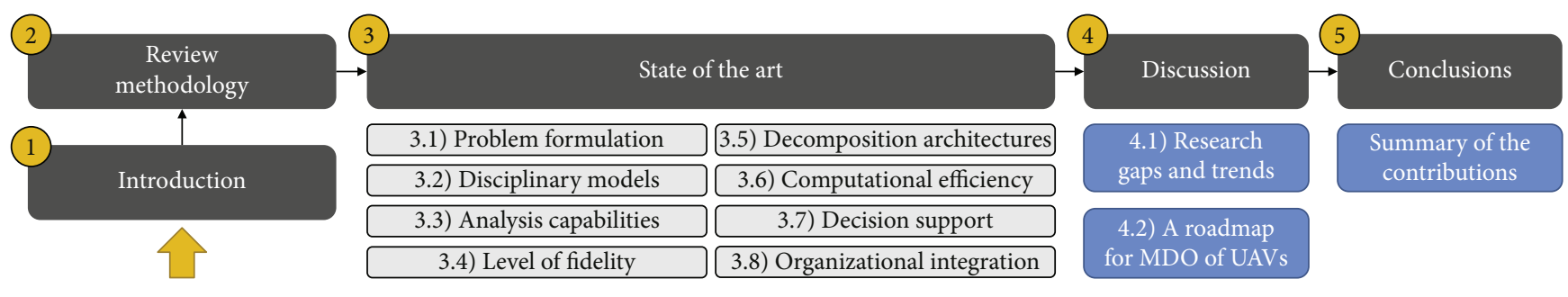

FIgURE 2: Overview of the structure of the paper and breakdown of the chapters.

design attributes but also by considering a representative set of design variables that are relevant to each application [1]. Thus, it becomes increasingly important for any MDO practitioner to understand and correctly interpret the given design requirements, to constrain the problem in a way that can ensure the realism of the final design, and lastly, to select the right design variables that can cover the intended design space without adding any unnecessary complexity [9].

3.1.1. Optimization Objectives. In the optimization of aerial vehicles, the most frequently used objectives are directly related to the overall operation of the design, and it can be seen that the majority of case studies often consider an objective which is directly related to weight, aerodynamics, or mission performance (see Figure 3). According to the findings of this review, weight indexes are by far the most preferred metric since they have been used in 67 case optimization studies $(39 \%)$, and the main reason is that they can be a good overview of many critical design requirements, like for example, the cost and the mission efficiency [12-16]. Here, the most commonly used approach is to consider a single objective, but it is also possible to combine several objectives through an aggregated function or formulate a multiobjective problem which can generally be a more flexible alternative for design space exploration $[13,17]$.

3.1.2. Design Variables and Constraints. In addition to the above, a common approach that can guarantee the correct exploration of the design space is to use a representative set of design variables as well as a proper set of constraints in order to ensure the realism of the final configuration [10]. Generally, including a high number of parameters can enable a more in-depth analysis of the design which can be useful in later stages, but on the downside, it can also increase the complexity of the problem which can then have a major effect on the efficiency of the optimization $[9,16]$. In this respect, it 


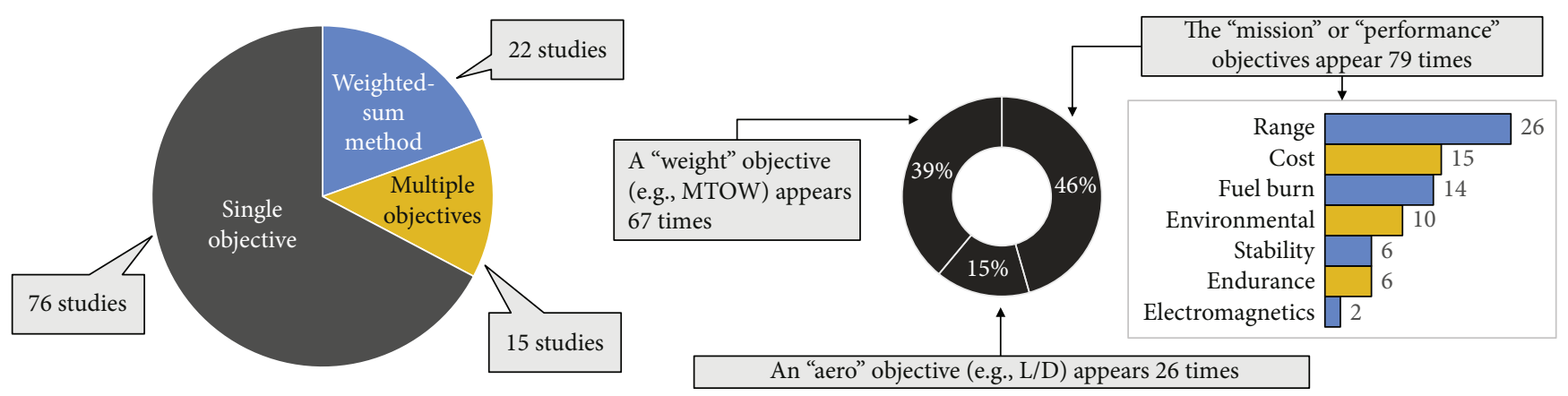

FIgURE 3: The reoccurrence rate of the different problem formulations (left) and types of objectives (right).

has been stressed that a sensitivity analysis of the design variables on the objectives has often been neglected, but should always be carried out before any optimization [18]. Overall, it has been shown that this approach has the potential to determine the design variables with the highest influence, and therefore, it can reduce the total parameters to a number that is relevant but also manageable for each specific case study [19-22]. As far as the constraints are concerned, those are usually limited to the critical case-depended features $[16,23]$ or similarly, to common airworthiness aspects like the field performance [13, 24-26]. In general, constraints can add further fidelity to the design, and this has been often exemplified through the incorporation of safety regulations in the modeling of fuel systems [27], aircraft controls $[28,29]$, and mission requirements for general aviation $[25,30,31]$.

3.2. Disciplinary Models. In order to enable a basic MDO of complex engineering products, it is first and foremost essential to be able to develop the necessary disciplinary models which will in turn be used as the building blocks of the optimization framework [32]. The number and complexity of the models depend on several factors, while as a general rule, it can be observed that this is often aligned with the design requirements of each particular application. Overall, there is a specific type and number of models which are typically included in MDO studies of aerial vehicles (see Figure 4), whereas at the same time, it is reported that there is a need to explore more features in order to allow for specific requirements to be considered $[10,11]$.

3.2.1. Common Disciplines. The first and most frequently encountered set of models in MDO of aerial vehicles are the calculation of aerodynamics, the estimation of the weight, the computation of the structural response, and lastly, the assessment of the propulsion specifications. In the conceptual design stage, it is common to use simple and fast aerodynamic predictions which can be provided by empirical equations $[24,28]$ or panel methods [33, 34]; however, in cases where more detailed insights into the design are required, it is often shown that computational fluid dynamics (CFD) codes can be a more accurate and hence suitable alternative $[35,36]$. Similarly, in the initial design phases, the weight and balance are estimated by using empirical equations [24, 37] as well as statistical data [38, 39], while for additional fidelity, it is also possible to augment the calculations by using the results of simplified [40-42] or full $[33,43]$ structural analyses. In this respect, the assessment of the structures is typically relevant only in detailed design applications where increased fidelity is required [32, 44], and for that reason, the models are built by using advanced computational structural mechanics (CSM) simulations and by considering an extensive list of structural elements and parameters [35, 45-47]. To this date, the structural analyses are solely focused on the wing $[27,36]$, and their main advantage within a MDO framework is that they can be used either to directly calculate the strength $[27,44]$ or to provide additional data for further static as well as dynamic aeroelastic computations [48, 49]. Finally, the propulsion specifications can be expressed in high-fidelity applications through a dedicated simulation model that considers the entire $[12,17,26,50-53]$ or an isolated part $[38,54,55]$ of the engine's operation, but for faster optimizations, it is also efficient to use statistical approximations [43, 45] or "rubberized" engines by means of scaling factors [16, 32, 56].

In addition to the above, a second set of models was also identified as common; however, the main difference here is that they are typically used as support elements to either complement or to enhance the calculations and thus close the optimization loop in a way that is meaningful to the design team. The first example of this is a dedicated model for the geometry which aims to provide a central representation of the aircraft in order to be used by other analyses like for instance in aerodynamics or structures [12, 41, 45, 57-59]. Overall, a fast and robust geometry model that is also compatible with the other disciplines is often stressed as one of the main enablers for a seamless MDO [17, 35, 60, 61], while at the same time, it is important to be able to capture the given problem [27] and have a flexible parametrization that can not only cover the design space but also offer the desired level of detail $[32,55,56,62]$. Secondly, it can be seen that a model for the stability and trim is usually present in the majority of MDO frameworks so that the trimmed state can be identified and ensure that the optimizer compares designs which share acceptable stability characteristics $[17,63,64]$. In its simplest and fastest form, trim is achieved through iterations of the control surface parameters [30, 33, 44, 47, 65, 66], whereas stability can be quantified by using empirical equations which calculate the stability derivatives $[26,39$, $54,61,67,68]$ or metrics such as the static margin (SM) 


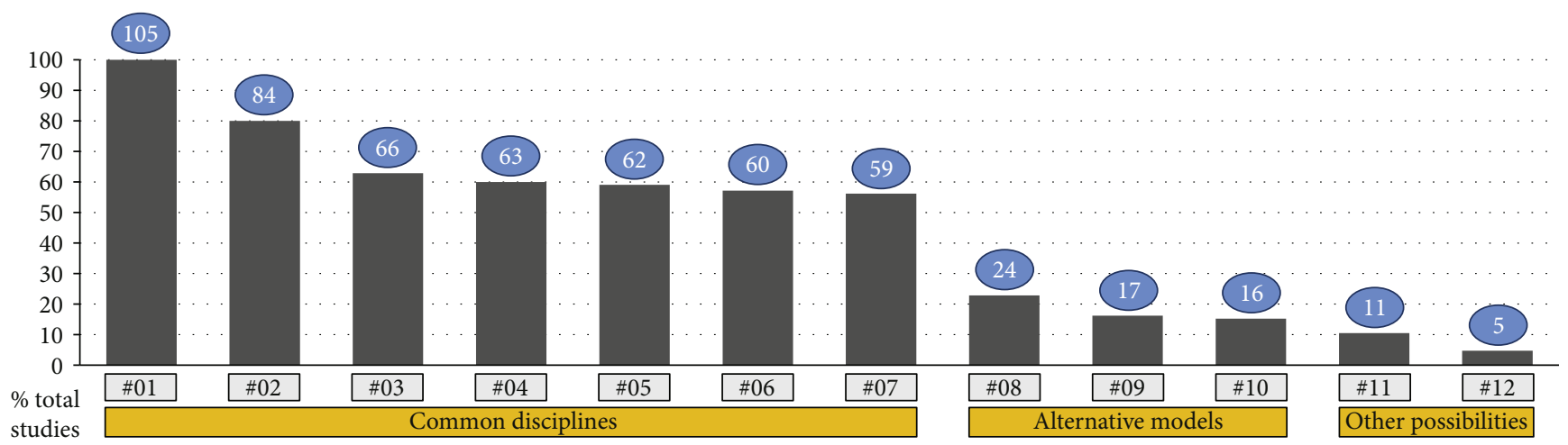

\#01: Aerodynamics; \#02: weight estimation; \#03: structural analysis; \#04: propulsion; \#05: geometry; \#06: stability and trim; \#07: mission performance; \#08: environmental impact; \#09: flight dynamics; \#10: cost and life cycle; \#11: subsystem simulation; \#12: electromagnetics

Number of studies that

include each discipline

FIGURE 4: The main categories and the reoccurrence frequency of the disciplinary models.

$[37,38,69]$. Lastly, once sufficient weight, aerodynamic, and propulsion data are available, the mission performance is typically assessed $[32,41]$, and for all design stages, this is usually done by dividing the mission into distinct steps and then calculating the energy to fly each segment by using either analytical expressions $[12,15,16,38,58]$, numerical simulations $[24,50]$, or a combination of both $[28,56]$.

3.2.2. Alternative Models. The environmental impact is an aspect which is increasingly being considered in the development of aerial vehicle applications, and as a result, it can be observed that some MDO frameworks have included a model in order to be able to capture its effect on the design. In total, there are two possible ways of measuring the environmental performance, and those are the estimation of the harmful emissions that are generated from fuel burn $[38,53,54,56$, $70]$ and the noise that the engine as well as the airframe generates on the ground $[35,41,55,58,70-73]$. Overall, the advantages of considering such a model become clear if specific requirements like airport and community regulations must be taken into account $[17,38,71-74]$, while to this date, the common approach is to use empirical equations for the emission calculations $[38,70]$ and advanced finite element solvers $[35,41,55,58]$ or analytical expressions $[26,70]$ for the phenomenon of noise propagation.

Moreover, an approach which can further enhance the quality of the design is to include a dedicated flight mechanics model which can take into account the interactions between the control surfaces, the control system, and the dynamic behavior of the aircraft. By considering those disciplinary aspects earlier, the synergies between controls and airframe can be identified during conceptual design, and therefore, it becomes possible to reduce the costly modifications which are traditionally required when this comes as an afterthought in the later development stages $[29,75]$. On the downside, such complex integration can pose a number of challenges for the MDO process, and in fact, it can be seen that there is no obvious figure of merit that can be used as an objective, while at the same time, it is often necessary to perform numerous, and possibly unaffordable, analyses in order to cover the entire flight envelope [28]. To this end, the coupling between aerodynamics, structures, and flight mechanics has shown very promising results for the overall design quality $[29,33,36,76,77]$, and the most notable methods of integration include the decomposition of the mission into different segments [28], the alleviation of loads through aeroservoelastic optimization [51, 75], the exploration of innovative control configurations $[43,78]$, and the assessment of handling qualities through the incorporation of military standards [28, 67, 78].

Finally, a further addition that can help engineers understand the economic implications and bridge the gap between technical and financial disciplines is to consider a model for the cost of a specific mission or of the entire product life cycle [23]. In aerial vehicle design, cost calculations are commonly based on empirical equations and statistical data which generally offer fast estimations [34]; however, the main disadvantage is that they are typically valid for a limited number of configurations and they usually omit how the product will evolve over time $[38,54,73]$. Thus, it can be observed that many authors are enhancing the traditional MDO frameworks with supplementary financial computations, and it can be seen that aspects such as the R\&D and production planning $[38,54,56]$ as well as the direct and indirect operating costs $[13,32,79,80]$ are crucial factors which can often drive the final design. In a similar way, additional knowledge can be obtained by modeling the behavior of the stakeholders through either a deterministic [24] or stochastic [81] market model, and overall, it has been shown that this value-driven approach can enable a better and more focused assessment of specific business risks which has not always been possible in the traditional performance-based MDO.

3.2.3. Other Possibilities. An aircraft is a complex product that is typically comprised of many subsystems which interact with the airframe as well as with each other, and hence, aircraft systems are inevitably a design driver that must be 
taken into account as early as possible in the development process [23, 46]. Nevertheless, aircraft systems are seldom considered in MDO, and apart from the complete study of [82], the rest of the papers either neglect them or focus only on a few specific aspects like for example the hydraulics [83], the environmental control [76, 84], the fuel supply $[27,84]$, or the landing gear $[46,85]$. Overall, it can be observed that in conceptual design it is common to model systems with simple equations which can predict the basic properties at a low computational cost, however, in detailed design, it can be seen that this approach is no longer adequate since it is critical to know the exact performance of each component [84]. In this respect, it has been shown that including a detailed system representation and performing a simulation-based optimization can generally offer significant knowledge on the design $[76,82,84]$, while at the same time, it is also possible to use the geometry in a collaborative way in order to identify the optimum layout [46] or detect unwanted issues that might arise during placement $[27,83,85]$.

In addition to this, a discipline which has also been neglected in MDO frameworks for aerial vehicle design is that of electromagnetics, and at present, there is a very limited number of papers where a model for measuring the radar signature and the antenna/sensor performance has been taken into consideration. Depending on the design stage, it can be observed that both simple equations [20, 86] as well as high-fidelity optic codes $[12,86,87]$ can be effective tools, whereas a common simplification which can make the process faster is to perform the analyses only in a small number of directions that are critical for each scenario [87]. Overall, it can be seen that modeling the radar signature becomes increasingly important when the stealth features [12] or the survivability [87] are included in the list of design requirements, while in a similar way, antennas and sensors can be a critical aspect when the focus is either on the communication [86] or the surveillance [20] capabilities, respectively.

3.3. Analysis Capabilities. A very common approach which has been followed in several of the referenced case studies and can enable a more accurate and holistic view of the design is to include one or more supplementary analysis capabilities (see Figure 5). Similarly to the disciplinary models, the aforementioned features are able to provide additional information regarding specific requirements which have been deemed critical for each design [88], and hence, they can offer further as well as valuable knowledge during the decision-making process [32]. In general, the analysis capabilities are not typically expressed through a model in the traditional sense, but instead, it can be observed that they are usually a combination of framework elements which have been structured in a specific way so that more complex computations can be performed. Consistent with this definition, the term analysis capabilities is used herein to indicate a function which aims to solve a particular problem in order to increase the fidelity of the results, and in this respect, it can be viewed as a means towards achieving an expansion of the MDO possibilities [11].
3.3.1. Aeroelastic Analysis. One of the most common analysis capabilities that is taken into account in MDO frameworks for aerial vehicle design is to consider the concurrent evaluation of aerodynamics and structures in order to make better estimations regarding the aeroelastic state of the lifting surfaces $[35,36,89]$. The main challenge herein is that the aerodynamic loads and the structural deformation are closely coupled, and therefore, it is especially critical in wing design applications to find a good equilibrium which does not generate unwanted effects such as load redistribution or flutter [1, 47, 66]. In general, the study of aeroelasticity becomes increasingly important in the later stages of the design which typically require additional accuracy $[62,88]$, and overall, it has been shown that it can be an essential part of MDO, especially when the focus is on the design of flexible [63], large surface area [48], and high aspect ratio [90, 91] wings.

The most straight-forward approach to identify the static aeroelastic conditions is based on an iterative loop which uses fixed-point iterations in order to evaluate the aerodynamic and structural responses until a convergence state is reached $[79,89]$. On the whole, the models which are employed in aeroelastic analyses should be able to capture the physics of the problem at an augmented level of detail [32], and for that reason, the most typical approach is to employ high-fidelity CFD and CSM codes which can ensure that the flow conditions and the mechanical deformations are accurately simulated [36]. In this respect, the study of aeroelasticity as an additional capability can generally offer significant knowledge on the design $[63,74]$, but on the downside, it can also induce further analysis demands which can clearly become very computationally expensive if numerous loading conditions $[35,88]$ or flight regimes have to be considered $[45,92]$.

To this end, there are several techniques which aim to make the aeroelastic analysis more efficient, and it has been shown that significantly faster results can be obtained if the estimation of the aerodynamic loads is replaced with a metamodel $[46,51,90]$ or if several load cases are distributed in parallel computers [35]. In addition to this, it can be seen that it is possible to use interpolation splines based on a radial basis function (RBF) in order to effectively transfer the aerodynamic loads and consequently reduce the mesh connectivity incompatibilities between CFD and CSM when complex configurations must be considered [32, 35, 36, 45, $48,62-64,68,91]$. At the same time, it can be observed that the formulation of an adjoint equation can help to efficiently compute the sensitivities in problems which have a very high number of design variables and accordingly lead to considerable computational savings when coupled with a gradientbased strategy $[32,35,65,93,94]$. Finally, as far as dynamic aeroelastic phenomena like flutter are concerned, those can be adequately captured with the $\mathrm{K}$ and PK methods, and in particular, this is typically achieved by computing the eigenvalues and eigenvectors for user-specified frequencies $[35,63,64]$ or by solving the eigenvalue problem for certain critical velocities [47-49, 95, 96].

3.3.2. Structural Layout Optimization. A feature which has been taken into account in a small number of case studies 


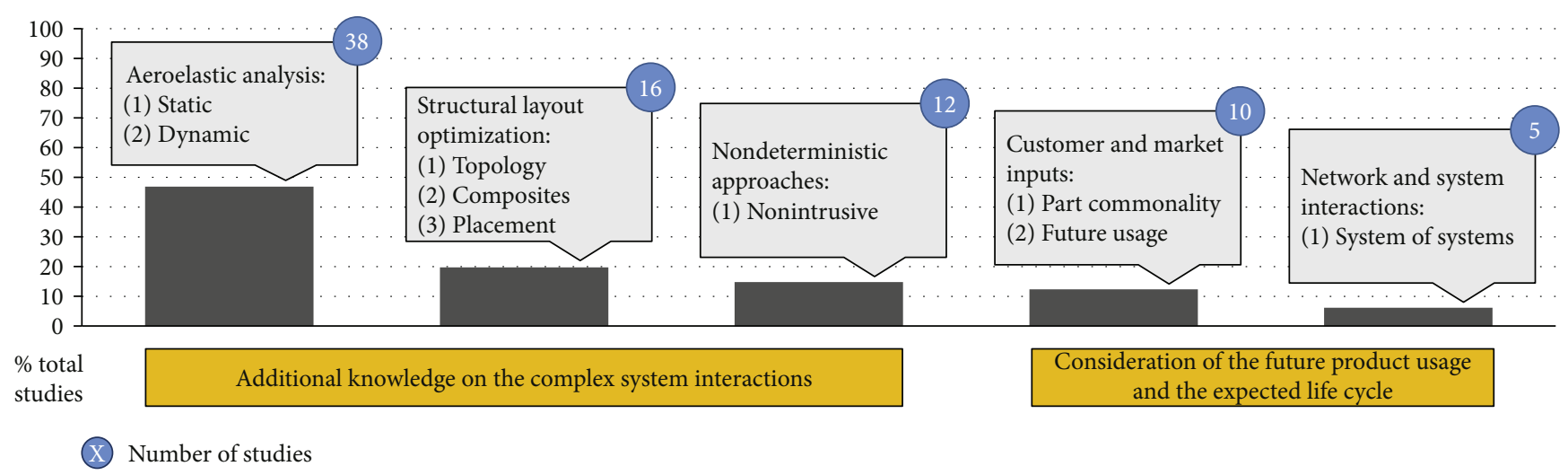

FIgURE 5: The main categories and the reoccurrence frequency of the analysis capabilities.

is to implement a dedicated and typically nested analysis in order to allow for a more detailed representation of the structures. In principle, the main advantage of this capability is that it can increase the level of fidelity regarding the details of the structural layout, and subsequently enhance the optimization by introducing additional information which would normally be available at the later design stages $[32,48]$. Generally, the optimization problem is about the improvement of the weight against several stress constraints, and the main area of its application is typically the wing or the wingbox system since they are viewed as the most critical parts of the structure. Although, the above additions can enable better knowledge on the design, they also have the main disadvantage of requiring a very high number of design variables which can inevitably increase the complexity of the optimization $[45,47,48]$. In this respect, it can be observed that structural optimization in MDO has not been fully integrated, and to this date, the most efficient solution that is used by practitioners is to break down this problem by considering a hybrid architecture with one or more local subprocesses [44].

In total, there are three main areas of application of the above type of analysis, and the most characteristic examples include the consideration of topology optimization, the use of composite materials, and the definition of the structural layout. The ultimate objective in all the aforementioned applications is the reduction of the structural weight, and in theory, this is achieved by increasing the structural strength in the critical loading points and decreasing it in the noncritical sections. In topology optimization, the idea is that there should be a more efficient use of material, and this is determined by identifying the critical loads and in turn adjusting the use of material thickness and density [48, 71, 97]. Similarly, in the use of composites, the goal is to use the most effective elements, and hence, the challenge here is to find the load directions and subsequently develop composite skins that have the best ply thickness and orientation [14, 49]. Lastly, the definition of the structural layout is about the optimum placement and dimensioning of the wing elements, and to this end, this is enabled through the use of a more flexible design automation that allows to move the wing parts (stringers, spars, and ribs) and accordingly explore unconventional configurations [14, 32, 44, 79].
3.3.3. Nondeterministic Approaches. An analysis capability which have illustrated a positive effect when included in MDO frameworks for aerial vehicle design is the implementation of nondeterministic methods, or in other words, the consideration of uncertainty. Two main categories are generally identified herein, and those are the robust design optimization (RDO) and the reliability-based design optimization (RBDO) which, respectively, aim to decrease the sensitivity to variations in operation and reduce the probability of failure in potentially critical conditions [6]. In general, robustness of the objective function has been emphasized more since it is crucial to have insensitive designs; however, it is also possible to treat constraints as probabilistic entities through a reduction of the feasible region or a probabilistic analysis [98]. In the design of aerial vehicles, uncertainty is first introduced to the system because of inadequate model structure like, for example, incomplete knowledge of the system or programming shortcomings [99], while the second and most common source is the inherent fluctuations of the real-world inputs like for instance, the potential variations in propulsion $[19,24,72]$, aerodynamics $[24,36,72]$, performance $[21,50,100]$, and market demands $[42,81]$. To this date, there are two available methods for estimating probabilistic entities, and those are the "intrusive" which considers changes to the models so as to directly incorporate uncertainty into the system, and the "nonintrusive" which treats the models as black boxes in order to generate a sample that can be used to compute the likelihood of the output $[6,98]$.

Nonintrusive approaches are the most frequently used due to the fact that they have the main advantage of being very simple, and in this respect, the most common tactic is to follow a RDO formulation where the aim is to minimize the sum of the mean and standard deviation of a certain optimization objective $[21,24,36,72,99]$. Similarly, in RBDO the aim is to minimize the likelihood of the constraint violation that may be caused by uncertainty in the variables or the parameters, and more specifically, it is possible to treat uncertainty as a random variable which follows a probability distribution function [101] or as a fixed interval when the probability distribution is unknown [50, 100, 102]. In the aforementioned formulations, the uncertainty of the input variables can be typically generated by using the Monte Carlo sampling method which in general is easy to implement 
$[72,99]$, but on the other hand, it has the main disadvantage of requiring a large number of samples to achieve stochastic convergence $[19,24,103]$. In view of that, promising results have been reported from the use of efficient sampling methods like the modern design of experiments (MDOE), and indeed, it can be seen that compared to a traditional DOE (e.g., full-factorial design), the required analysis time can be greatly reduced if only a small number of algorithmdistributed critical points have to be simulated [24]. Accordingly, there are several alternatives that can further reduce the computational cost, and it has been shown that it is possible to replace the probabilistic constraints with metamodels $[19,22,36]$ and to evaluate and subsequently limit the uncertainty sources through an initial sensitivity analysis $[19,50,72]$.

3.3.4. Customer and Market Inputs. A relatively uncommon analysis capability that this review identified is connected to the particulars of the customer preferences as well as the marketing of the product, and more specifically, to the possible ways that this aspect can be expressed in the MDO process. Here, the main objective is to explore how the intended operation or the target market can affect the design, and two indicative examples are to either take into account the commonality of the parts or consider how the future usage of the product should be. The study of commonality is typically addressed by means of adding specific figures of merit in the objective function $[67,104,105]$, and it can be performed by using solely the available information of the early design stages [46]. The main advantage of considering families of products is that it can enable a further exploration of the design space between technical and economic aspects [46, 105], while a possible disadvantage is that a more efficient decomposition strategy may be required if high-fidelity models are included in the framework [104]. As far as the future usage is concerned, it can be seen that this is commonly expressed by an analysis of the trajectory in its twodimensional form, and as such, the main limitation is that it is exclusively relevant to the energy equilibrium that corresponds to each mission. To this end, this representation is computationally efficient and offers sufficient detail in order to be used in the minimization of fuel $[70,106]$ or emissions $[53,54]$, but it can become inadequate when spatial information is required, like, for example, in the simulation of tactical scenarios [20] and noise propagation [71].

3.3.5. Network and System Interactions. An analysis capability with a low reoccurrence rate in MDO for aerial vehicles is the simulation of designs in a system of systems (SoS) context, or in simple terms, the development of products by taking into account a higher and thus more abstract level of independent system interactions [71]. In general, the main challenge of SoS synthesis is that numerous self-contained elements with computationally expensive models must be concurrently analyzed in order to provide answers regarding a set of capabilities [107]. At the same time, it is also important to develop a framework structure which allows information to flow in a bidirectional way, namely from the higher or SoS level down to the system as well as subsystem level [71].
As a result of this, a multilevel architecture has been commonly identified as the most appropriate approach, and it can be seen that an efficient decomposition strategy is to have the main SoS linear programming problem on top and then delegate the design optimization to one $[42,107]$ or even two layers of analysis [71, 108]. Overall, including a SoS formulation in MDO can enable a tighter coupling between the design of aerial vehicles and their actual synergies during operation [42], and two representative examples of this in real-world scenarios are the minimization of noise around airports [71] and the allocation of a fleet to specific air routes $[42,80,107,108]$.

3.4. Level of Fidelity. The level of computational fidelity that the framework functions and models can deliver is undoubtedly a critical factor which can affect the ultimate success of MDO [9]. In a nutshell, it is essential to be able to capture the correct physics of the problem at hand $[18,27,40,63$, 103], while at the same time, it is equally important to have tools that can deliver fast and robust calculations [12, 38, $41]$. On the whole, the fidelity of the tools is primarily determined by the development stage that the MDO aims to improve [46], and as a result, it is always crucial to consider the degree of design maturity that has already been or needs to be established [32]. The final choice of tools is in the hands of the end user, and for that reason, the commonly accepted approach is to develop modular frameworks which can enable the design team to add new models or to switch between different levels of fidelity [2, 13, 14, 57, 58, 61, 74]. To this date, there have been many advancements in both software and hardware which allow for the development of even more efficient tools, and according to the findings of this review, a list of the most popular options for aircraft MDO has been compiled in Figure 6.

3.4.1. Low-Fidelity Tools. Overall, it can be observed that lowfidelity tools are the most frequently implemented solution in the majority of the reviewed MDO case studies. Clearly, the rationale behind this tendency is that simpler models can provide sufficiently good predictions for the majority of basic aircraft disciplines, while at the same time, they can generate very fast results which is an undeniably vital element in conceptual design [30, 38, 41, 57, 73, 79, 89]. Nevertheless, low fidelity can also have many disadvantages, and in fact, it can be seen that it is often impossible for simple tools, like for instance some empirical weight and aerodynamic codes, to give accurate computations of the involved phenomena $[12,18,63,92,103]$. One good example of this is according to $[31,39,63,77,89,97]$ the vortex lattice method (VLM) which offers fast computational times, but it is only valid in certain flight regimes and it does not take into account the compressibility, parasitic, or interference drag. In general, the limitations of low fidelity become especially critical when unconventional configurations beyond the prediction range have to be analyzed $[27,50,76]$, but it can also be a major drawback in the later stages of the development process where a higher level of design detail is usually a basic requirement $[32,46,84]$. 


\begin{tabular}{|c|c|c|c|c|c|}
\hline & Conceptual design & & Preliminary design & & Detailed design \\
\hline & L1 (low fidelity) & & L2 (medium fidelity) & $\begin{array}{l}\mathrm{L} . .3 \\
\end{array}$ & L3 (high fidelity) \\
\hline Aerodynamics & $\begin{array}{l}\text { Panel codes } 52 \% \\
\text { (e.g., TORNADO [122]) }\end{array}$ & \multirow{4}{*}{$\begin{array}{c}\text { Meta } \\
\text { models of } \\
\text { level } 2 \text { or } \\
\text { multi } \\
\text { fidelity } \\
\text { process } \\
\text { between } \\
\text { levels } \\
2 \text { and } 1\end{array}$} & $\begin{array}{l}\text { Euler solvers or } \\
\text { coarse CFDsimulations }\end{array}$ & \multirow{4}{*}{$\begin{array}{c}\text { Meta } \\
\text { models of } \\
\text { level } 3 \text { or } \\
\text { multi } \\
\text { fidelity } \\
\text { process } \\
\text { between } \\
\text { levels } \\
3 \text { and } 2\end{array}$} & $\begin{array}{l}\text { Full CFD simulations } 37 \% \\
\text { (e.g., ANSYSFluent [128]) }\end{array}$ \\
\hline $\begin{array}{c}\text { Weight } \\
\text { estimation }\end{array}$ & $\begin{array}{l}\text { Empirical formulas or } 77 \% \\
\text { history data (e.g., }[123,124])\end{array}$ & & $\begin{array}{l}\text { Estimation tools } \\
\text { (e.g., FLOPS [130]) }\end{array}$ & & $\begin{array}{l}\text { Data from the CAD } 10 \% \\
\text { or CSMmodels }\end{array}$ \\
\hline $\begin{array}{l}\text { Structural } \\
\text { analysis }\end{array}$ & $\begin{array}{l}\text { Textbook equations } 17 \% \\
\text { or beam models (e.g., [125]) }\end{array}$ & & $\begin{array}{l}\text { Global CSM analysis } 13 \% \\
\text { (on a simplified geometry) }\end{array}$ & & $\begin{array}{l}\text { Detailed CSM analysis } 70 \% \\
\text { (e.g., NXNASTRAN [127]) }\end{array}$ \\
\hline Propulsion & $\begin{array}{l}\text { Statistical data or } 58 \% \\
\text { rubber engines (e.g., }[126] \text { ) }\end{array}$ & & $\begin{array}{c}\text { 1D engine } 24 \% \\
\text { simulation (e.g., NPSS[129]) }\end{array}$ & & $\begin{array}{l}\text { Thermodynamic and } 18 \% \\
\text { flow simulations }\end{array}$ \\
\hline Geometry & \multicolumn{4}{|c|}{$\begin{array}{l}\text { Mathematical representation of the geometry } \\
\text { (e.g., cloud of points or surface models) }\end{array}$} & Full CAD detail \\
\hline $\begin{array}{l}\text { Stability and } \\
\text { trim }\end{array}$ & \multicolumn{2}{|c|}{$\begin{array}{c}\text { System of linear } \\
\text { equations for trim and stability }\end{array}$} & \multicolumn{3}{|c|}{$\begin{array}{l}\text { Stability and control derivatives, Critical } \\
\text { load cases and maneuvers, trajectory analysis }\end{array}$} \\
\hline $\begin{array}{c}\text { Mission } \\
\text { performance }\end{array}$ & \multicolumn{2}{|c|}{$\begin{array}{l}\text { Empirical equations for the } \\
\text { field performance characteristics }\end{array}$} & \multicolumn{3}{|c|}{$\begin{array}{c}\text { Discretized numerical simulations or } \\
\text { specialized performance calculation software }\end{array}$} \\
\hline
\end{tabular}

FIgURE 6: Example of the tools that are typically used in the disciplinary modeling of aerial vehicle MDO.

3.4.2. Medium-Fidelity Tools. In general, the medium-fidelity tools are solutions which aim to provide sufficiently accurate results at a reasonable computational expense, and to this end, the main trend here is to either implement more refined low-fidelity simulations or to rely on a simplified highfidelity analysis. This can be clearly seen in the case of aerodynamics as well as structural analysis, where a common approach is to use Euler solvers [43, 63], higher-order panel codes $[12,59]$, or coarse CFD simulations [97] in the first and global CSM analyses [43] or simplified geometries $[40,45]$ in the second. For this phase of the development process, the estimation of the weight and the mission analysis are also based on more advanced computational tool packages which offer a number of sizing alternatives [12, 61], while the engine performance is calculated by means of simple one-dimensional simulations that can evaluate the thrust and the consumption at a variety of flight conditions [20,38]. Lastly, in most applications, there is a dedicated, but yet simplified, surface geometry model in order to close the optimization loop or provide visualization of the design [56], whereas in addition to this, the framework is now enhanced with further stability and trim modules which offer a more thorough analysis of the aircraft's performance in critical manoeuvers $[28,76]$.

3.4.3. High-Fidelity Tools. In contrast to the above, highfidelity tools are not always a popular solution, but it has been demonstrated in several case studies that their implementation can help increase the level of confidence in respect to the design $[9,30,46]$. For most authors, the ultimate goal is to efficiently integrate high-fidelity models as soon as possible in MDO and subsequently reduce the uncertainties of decision-making even at the earliest stages of the development process $[32,64,84]$. High-fidelity analyses are highly suitable for the exploration of novel concepts $[40,46,55,63]$, but they can also support the modeling of critical design requirements, like, for example, the accurate analysis of aerodynamic and structural interactions $[35,36$, $46,63]$. On the downside, higher fidelity is typically associated with increased computational requirements [32, 101, 103], while at the same time, it is argued that a relatively higher number of integration issues is likely to occur due to their inherent interface complexity $[18,61]$. Finally, highfidelity tools are also expected to require the engagement of domain specialists in order to develop advanced models which in general, means that this type of projects is anticipated to have increased collaboration requirements but also to suffer from prolonged development times $[76,84]$.

3.5. Decomposition Architectures. In order to solve any MDO problem, a suitable architecture or strategy must first be established. The primary function of architectures is to define the couplings between the disciplinary models but also to indicate how and in what sequence the overall optimization problem will be solved [5]. On the whole, the ultimate choice of architecture will primarily depend on the complexity of the problem, while other critical selection factors can be the availability of a particular algorithm, the presence of approximation models, and the access to computational resources [5]. To this date, research on MDO architectures for complex engineering products has been very extensive, and at present, there is plethora of decomposition methods which can be used to tackle problems with strong couplings among the disciplinary models (e.g., MDF, CO, BLISS, ATC, and CSSO). In the following sections, the most commonly encountered strategies in aircraft MDO will be presented, while for further information on this topic, the interested reader is encouraged to refer to the comprehensive survey which can be found in [5].

3.5.1. Multidisciplinary Feasible. As far as aircraft design optimization is concerned, it can be seen that the most commonly used architecture is typically a variation of the monolithic multidisciplinary feasible (MDF) formulation [3]. The 
reason for this is that $\mathrm{MDF}$ is simple to implement, there is always system consistency at the end of every iteration, and the global optimizer is in direct control of all the design variables and constraints [5]. On the downside, MDF is based on fixed-point iterations, and as a result, it requires a full analysis cycle for every one of the global evaluations which in turn can be a very computationally expensive process when timedemanding analyses or complex disciplinary couplings are considered $[3,5]$. A common application of MDF in aircraft design is the decomposition of coupled disciplines, and the most typical example of this is the concurrent evaluation of the mission performance (fuel requirements) and the estimation of the total weight $[12,16,25,37,45,50,109]$. Accordingly, further uses of the MDF architecture include the decoupling between performance and propulsion $[12,18,51]$, aerodynamics and stability $[12,61]$, and lastly, structures and loads which is a very common requirement when an accurate aeroelastic state must be determined $[32,35,36,45,60,88,90,92,110]$.

3.5.2. Collaborative Optimization. A frequently encountered formulation which has the potential to tackle the aircraft design problem is the collaborative optimization (CO) architecture [3]. CO is a distributed architecture which is based on a variation of the individual discipline feasible (IDF) formulation but with the difference that each subprocess is an optimization instead of an analysis [5]. In general, CO has the main advantage of enabling a parallel analysis through problem partitioning; however, its main weakness is that the consistency constrains between the subproblems do not always guarantee that a feasible solution can be found [5]. The typical decomposition in aircraft design is usually discipline-based, and hence, the analysis of each model (e.g., aerodynamics, weight, and propulsion) is performed independently, and it is controlled by a subspace optimization $[15,91,111]$. In this way, it is possible to take advantage of parallel computing and thus multifidelity tools [112], while it is much more convenient to decompose the system, especially when complex interdisciplinary couplings have to be considered. Overall, CO can be applied in a variety of applications, and in fact, it can be seen that it is possible to partition an aircraft family design problem into family members [104] and also to simplify complex problems like control integration by considering each mission segment as a different suboptimization [28].

3.5.3. Asymmetric Approaches. An approach that has increasingly been used in the development of MDO frameworks for aircraft design is to partition the problem in a way that one or more local optimization processes are considered. Here, the local level optimizations are performed independently and for each one of the global level evaluations, but each level is controlled by an individual optimizer with different design variables, objectives, and constraints. This asymmetric method of analysis is based on the combination of both the MDF and $\mathrm{CO}$ architectures, and its main advantage is that it can reduce the complexity of the problem by decreasing the number of variables at the global level $[13,44,46]$. Further advantages include the possibility to perform multifidelity analyses in parallel as well as in different physical locations $[44,82]$, whereas a potential disadvantage is that the global optimizer loses some sensitivity towards the local variables and therefore, a lower overall performance is to be expected [46]. In total, local processes are an efficient method to enable detailed design loops into frameworks for conceptual studies, and the most notable example of this is in the optimization of the layout and the dimensions of the wing structural components [13, 14, 4446, 48]. Accordingly, local processes can be used for the optimization of the landing gears [85], the propulsion [13], the controls [75], and the onboard systems [82], while in addition to that, they can also be implemented in aircraftbased decompositions, like, for example, in fleet allocation [71] and SoS problems [107].

3.6. Computational Efficiency. In its role as a decision support tool, MDO should be able to provide fast answers in order to increase the available design knowledge at an even earlier stage in the design process [32]. As a result, achieving the highest computational efficiency is considered to be a key development aspect for any MDO framework [9, 113], and in this respect, it can be seen that the majority of the referenced case studies include methods which aim to improve the performance.

3.6.1. Metamodels. The most frequently implemented methodology that aims to increase the efficiency of the optimization is to use surrogate models or metamodels. In general, metamodels are based on statistical approximations, and their main scope of application in MDO frameworks is to increase the speed of the optimization by replacing the computationally expensive disciplinary analyses [3, 4]. Metamodels are usually created offline by domain experts, and the development process is to first identify the response of the original system at certain predefined points and then use an approximation technique in order to mimic its behavior throughout a larger design space $[1,9]$. Consequently, the main disadvantage of metamodels is that the predictions can sometimes have a large deviation from the real model, and some of the factors which can affect the final accuracy are the number of input variables [32], the amount of noise in the original function [4], and the type of distribution as well as the number of the input samples [84].

A common application of metamodels is to substitute the high-fidelity models and therefore increase the speed of the optimization while allowing for a larger set of design points to be considered in the process [30]. In total, metamodels have typically been used to replace complex aerodynamic $[31,37,41,46,90,91,94,95,114]$, as well as structural $[31,32,43,51,90,91,95]$ analyses such as CFD and CSM codes, and it has been shown that this approach can generally be a viable alternative at a minimum loss of accuracy. Similarly, metamodels can also effectively represent other complex elements of the framework, and in fact, they have been successfully implemented to estimate the dynamics of the aircraft systems $[83,84]$, the performance of the engine and the exhaust $[12,13,17,51]$, the noise and the ground boom 
propagation [41], and finally, the weight as well as the mission specifications $[17,22,43,52,69]$.

Overall, this review showed that metamodels are an important part in aircraft MDO, and in this respect, many authors have often explored a number of enhancement methods with the most common being to automatically recalibrate the models with new points after each iteration $[13,41,46,52,69,84,95,103,114]$. Another typical example of how one can improve the accuracy is to use local metamodels since they allow better approximations by focusing only in the areas of the design space that have been identified as the most critical for each application $[12,41,114]$. Accordingly, if the number of design variables is high or the function is difficult to approximate, it is also possible to decompose the problem into several smaller segments and then develop one metamodel that corresponds to each one of them. In this way, it becomes possible to maintain a high level of accuracy and still have fast processing times as it can be seen in the case studies of $[32,46]$ where a metamodel was created for every wing panel in order to estimate the aerodynamic and structural response, respectively.

3.6.2. Multifidelity Schemes. A multifidelity scheme which has been frequently implemented in MDO frameworks for aircraft design and has often shown promising results is to include one more high-fidelity processes in order to calibrate or enhance the predictions of the low-fidelity tools. The development methodology which is followed in these cases is to use the simple models to initially narrow down the design space and then to engage a set of detailed analyses in order to obtain more reliable calculations over a smaller region [26, 109]. The main advantages of this approach is that it firstly enables a quick exploration of the design tradeoffs at a complete discipline and aircraft level $[46,114]$, while secondly, it allows the consideration of unconventional configurations and the use of advanced physics in areas where this is truly needed $[27,32]$. Typical examples of this include the use of advanced aerostructural calculations [27, 32, 46, $72,88,109,114]$ and also the analysis of the case-specific critical design aspects like for instance, the propulsion [18], the environmental impact [72], and the communications systems [86] in order to correct the computed low-fidelity performance. On the whole, multifidelity structures can facilitate the transition between conceptual and detailed design $[32,88]$, and as such, the tools and the fidelity of each MDO level should be correctly selected so that they are aligned with the objectives and deliverables, as well as timeframes of each phase [46].

3.6.3. Distributed Calculations. An alternative that can increase the efficiency of the framework when the local hardware is already at its limits is to distribute the calculations over several computational units $[2,11,17,93]$. Provided that the optimization includes processes that can be executed in parallel, it becomes possible to take advantage of additional resources and thus make significant time savings by performing some of the analyses simultaneously $[36,39,44,46,64$, 91, 94, 106, 110]. Furthermore, this approach facilitates the decentralization of the framework, and therefore, it also enables to perform an optimization by using models which were developed independently by geographically separated teams of experts $[18,82,96,110,112,115]$. Nevertheless, parallelization can often have many disadvantages, and in fact, the final efficiency can often be limited by the network or data exchange speeds which are often the bottleneck [36]. Finally, given that distributed frameworks are a heterogeneous environment, specific translators are usually required to ensure data compatibility $[57,112,115]$, while in some cases, security protocols must also be considered in order to guarantee the integrity of the data [18].

3.7. Decision Support. One issue that has been stressed in many case studies regarding the application of MDO in the industry is the lack of adequate methods for postprocessing, validating, and visualizing the results in a manner that is adequate for each design stage and application [9]. To this date, it can be seen that the majority of researchers has focused on solving technical problems in order to prove the advantages of MDO, while conversely, it can be observed that the data management part, which is the most attractive for the industry, has yet to receive the appropriate attention [10]. As a result, an increasingly frequent demand by many authors is to develop frameworks which will be able to access the optimization data in an efficient and intuitive way [2], to visualize the design space in order to better assist in the decisionmaking process [7], and finally, to validate the results so that the end user can know the extent to which the optimized designs can be trusted [11].

3.7.1. Validation of Results. One very common issue with MDO is that the disciplinary simulations as well as the analysis capabilities are often based on simplifications [33], while in some cases, it is also possible to get computational errors due to an inadequate model integration [25]. On the whole, a validation process can insure the reliability of the design and provide supplementary confidence regarding the optimization $[41,50]$, but on the downside, it is also expected to increase the overall process time and require the input of additional teams like, for example, simulation or prototyping experts [63]. According to this review, there are three possible methods for validating the results of the MDO process, and to this end, the most common approaches are to either use high-fidelity simulations $[21,30,33,37,40,41,46,50$, $58,59,77,109,112]$; physical prototypes $[34,40,55,63,68$, $86,97,110,116]$; or data from similar aircraft $[12,17,21$, $25,26,79,85,91,92,101]$. As far as prototyping is concerned, it can be seen that MDO and additive manufacturing techniques can be easily coupled, and it has been shown that this approach can be a promising combination for both the validation of the results and for establishing a solid foundation towards further subscale tests [34, 40, 97, 116]. Overall, the particulars of each validation methodology are elaborated in Figure 7, and like many other aspects of the MDO process, it can be seen that the ultimate choice of validation technique is usually a tradeoff between the level of the desired accuracy and the required time. 


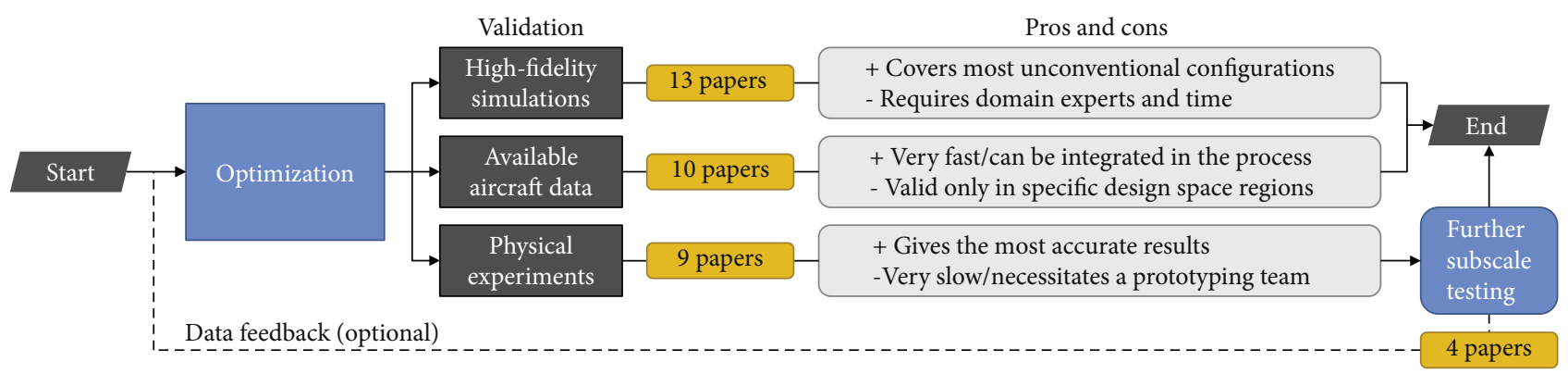

FIGURE 7: Overview of the three different validation possibilities.

3.7.2. Visualization of the Design Space. Visualization of the results is another essential postprocessing activity which primarily aims to present the optimization data in a suitable way that can be understood and subsequently analyzed by the design team $[9,32]$. In general, this task is straightforward when the problem is comprised of one or two objectives, and in most cases, the tradeoffs can be effectively visualized by using two-dimensional plots like, for example, the Pareto frontier [13, 32, 35, 38, 44, 46]. Nonetheless, if there are three or more objectives, the dimensionality of the problem becomes significantly higher, and as a result, a more appropriate visualization technique is often required to represent the complex design relations $[95,113]$. One example of the latter are the self-organizing maps (SOM) which use clustering together with contour lines in order to identify areas of interest in the design space and in turn enable an easier comparison of the synergies between design parameters and objectives [72, 95]. Apart from the above elementary and case-specific examples, this review has identified that visualization has not been properly addressed in a MDO context, while in total, it can also be observed that there is a research gap on postprocessing, and in particular, on tools which can be used to support the decision-making process.

3.8. Organizational Integration. Besides the practical aspects, an additional feature that can be of utmost importance for an effective implementation of MDO is to be able to seamlessly incorporate the optimization data into the product development process [8]. Generally, MDO has been applied in the design of numerous types of aerial vehicles, and it has shown improved performance results within all stages of the product development process (see Figure 8). In view of that, there is a number of challenges which have been identified even from the earliest days of MDO [1,9], and those are usually grouped into three broad levels of potential barriers which are namely the technical, the organizational, and the cultural. To this date, most of the MDO "advocates" have dealt extensively with the technical barriers which have proven to be the easiest to understand and address, but at the same time, this has created a biased research focus at the expense of the other two levels which have been overlooked in the majority of case studies $[8,11]$.

3.8.1. Technical Level. At a technical level, a typical approach which aims to enhance the design of aerial vehicles is to develop a generic optimization tool that can be effortlessly applied at different levels of fidelity in order to assist the decision-making process $[32,60]$. According to this review, there are several commercial and noncommercial solutions that can be used to achieve a seamless integration of the various disciplinary models [117-121]; however, the general trend that can be observed here is that authors tend to rely more on case-specific framework solutions which have been developed in-house so that they can provide further MDO capabilities for each organization $[26,36,56,63,64,113]$. The main challenge herein is usually associated with the integration of the various models, and more specifically, it is noted in $[2,7,113]$ that the optimization platform should have the ability to handle different storage formats, to propagate the change of variables, and to provide support for collaborative design decisions. Furthermore, it has been shown that features such as reusability and modularity can significantly increase the range of design applicability $[22,26,46$, $56,63]$, while at the same time, parallelization and remote management can, respectively, lead to more efficient processes as well as better collaboration between the involved actors $[36,39]$. Towards this end, considerably better results in terms of extensibility, ease of use, and scalability can be obtained by following an object-oriented approach $[26,56$, $61,64,115]$, whereas some additional small-scale improvements can also be achieved through the use of "smart" features, like, for example, historic data logs [14], job queuing systems [36], and decentral code management modules [60].

3.8.2. Organizational Level. At an organizational level, the design of aerial vehicles must typically go through a number of stages which usually engage several departments, and therefore, one of the main challenges for a successful MDO implementation is to be able to identify its capabilities but also its effect within each phase of the product development process [10]. Nevertheless, according to this review, the contribution of MDO in respect to the entire development process is seldom addressed, while at the same time, there is very limited research regarding the organizational issues which may arise in practical industrial applications. In this light, three principle design stages which are namely the conceptual, preliminary, and detailed are usually taken into account in MDO studies, and the most common organizational consideration is confined to the correct choice of fidelity level in order to be able to support the decision-making process $[18,46]$. Moreover, a few studies have also focused on the use of MDO as an efficient knowledge bridge between 


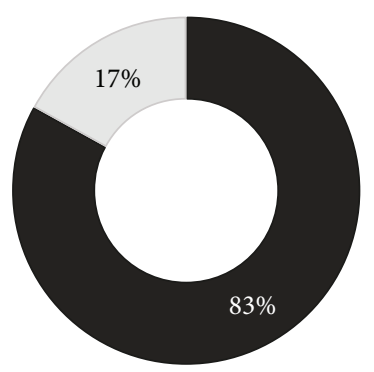

Academic Industrial

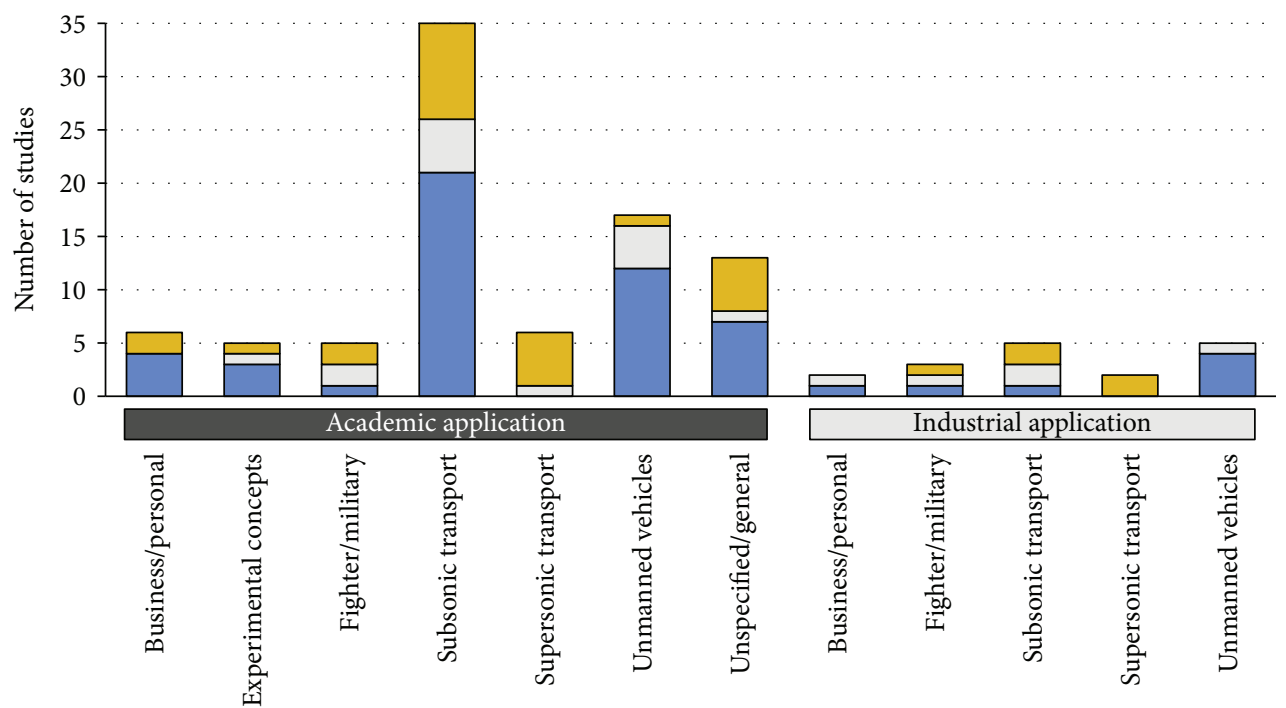

High fidelity

Multifidelity

Low fidelity

Figure 8: The different types of MDO applications and the corresponding intended level of design.

the conceptual and the detailed design stages, and it has been shown that the use of high-fidelity data at an earlier time can shorten and subsequently merge the intermediate stages of the development process $[32,40,60]$.

3.8.3. Cultural Level. At a cultural level, the two main challenges which have been frequently identified during the implementation of MDO are the issue of its integration in the organizational philosophy [8] and the issue of effectively rearranging the teams as well as the resources of the company $[9,66]$. Here, it can be observed that the cultural aspect of how MDO can be accepted in an industrial workplace has not been reflected at all in this literature sample, while at the same time, it can be seen that there have only been some very limited attempts towards the definition of the appropriate roles and the suitable team composition that can support the MDO process $[39,84]$. In this respect, it is first and foremost noted that the traditional teams of conceptual engineers are neither capable nor responsible for developing specialized disciplinary tools, and hence, the engagement of domain experts is often required in order to enable a more accurate exploration of the design space $[32,76,112,115]$.

\section{Discussion}

\subsection{Research Gaps and Trends}

4.1.1. Framework Elements. Starting with the review of the disciplinary models, the most important conclusion which can be drawn here is that a combination of the core aeronautical disciplines has always been the basis of any MDO framework for aerial vehicle design (see Figure 4). Here, there are no visible gaps in the modeling of the "common" disciplines, and the main research objective that is still shared by the community since [9] is to enable high-fidelity calculations while simultaneously reducing the total computational time. In light of this, it can be said that there is a clear research gap in disciplinary modeling, and thus two possible directions that can enable a holistic improvement is to guide the research towards more powerful capabilities and entirely new features as it has been previously suggested by [11]. To this end, it has been shown that disciplines for the environmental impact [38], the flight mechanics [75], and the cost estimation [24] have gradually started to be taken into account, while others like, for example, the system interactions [82] and the electromagnetics $[12,86]$ are still at a very elementary level. Nevertheless, there are also some design aspects which have not been properly expressed in MDO, and according to this review some examples of this type of modeling are the manufacturing process, the product maintenance, the operating environment, the evolution of the market, and lastly, the intangible entities like the aesthetics of the design.

As far as the analysis capabilities are concerned, it can be seen that they do not always constitute a standard element of a MDO framework, while it can also be observed that not all them have the same frequency of implementation (see Figure 5). Similarly to the findings of [10], this review found that there is an ongoing research in this field, but on the downside, there is also a need for more efficient processes as well as novel capabilities. To this date, aeroelasticity has received [1], and still receives, adequate attention since it is an important aspect of the wing design, but at the same time, the advanced structural analyses like topology optimization have not been yet included as a standard practice in MDO of aerial vehicles. Moreover, there is a need to further expand the existing nondeterministic approaches [6] since they have been often shown to be an important tool in the exploration of additional uncertainties like, for example, the undesirable system behavior, the effects of the operator, and the mission 
fluctuations. Finally, there is a lot of room for improvement regarding the front end of the development process, and thus, more research on the customer and market inputs as well as on the network and system interactions can be the logical next step towards more holistic optimizations and designs of better quality.

4.1.2. Optimization Performance. According to this review, the performance of the optimization is for the majority of case studies a critical point, and thus, it can be viewed as one of the most active areas of MDO for conducting further research. On the whole, the main trend in MDO is currently to be able to handle data of higher fidelity even in the early optimization runs, and the reason for this is that an erroneous assessment of the problem physics may lead to underperforming or nonrealistic solutions. Although this is generally accepted, it can be seen that some authors abstain from specifying the development stage that they aim to enhance, whereas for some others, the choice of models is often based on availability rather than suitability. Consequently, there is a need for a comprehensive study regarding the available software solutions as well as their potential integration issues, while accordingly, one further useful addition since [7] would be to redefine the framework requirements that correspond to the different stages of the development process.

To this date, the most frequent approach towards increasing the efficiency of MDO is to either implement metamodels or to decompose the problem through the use of architectures. The development of metamodels belongs to the field of machine learning; however, their popularity in MDO [4] has nowadays created new needs that in turn calls for further research on the possible alternatives for aircraft design frameworks. As far as architectures are concerned, it can be observed that the single-level strategies are generally preferred over the more intricate multilevel decompositions, and a recent tendency that is also reported in [3] is to use asymmetric optimizations or multifidelity schemes in order to reduce the computational time. Overall, the field of optimization architectures has been explored quite extensively [5], and in this respect, it could be beneficial to expand it to simulation-based MDO case studies in order to investigate the use of further strategies and provide more structured information regarding the existing solutions.

4.1.3. Development Process. One common and still reoccurring issue in the referenced literature as also stated in [8] is the trend to focus excessively on the technical aspects of MDO, whereas at the same time the organizational integration aspects of the method are either neglected or totally omitted. In particular, it can be observed that it is a very usual phenomenon to come across frameworks that are able to generate "better" designs, but it is never specified what kind of resources were required or how the design team can eventually use this information to make meaningful decisions. What is more, there are only a few case studies $[32,39,84]$ that have dealt with the roles as well as the cultural adaptation of $\mathrm{MDO}$, and therefore, it becomes clear that there is a need to prove how and to what extent the proposed tools can fit in the development process. In general, the severity of this research gap may not seem important for the purely technical publications, but nonetheless, it can be argued that excluding organizational aspects can be a significant, but yet underestimated, hindrance towards the complete integration of MDO in the manufacturing industry.

To this end, two very important activities as also reported in [9] are the validation of the results and the visualization of the design space, but it can be seen that those are seldom included in the referenced case studies. Apart from that, visualization methods are strictly limited to one- or twodimensional representation graphs, while it can also be argued that the simple validation techniques like the use of data from similar aircraft are not always a reliable source of information. Hence, there is a need to develop more flexible data management tools which will allow for a better exploration of the design space in a way that is meaningful to the decision-making team. Moreover, there is a need to take into account the back end of the development process, and a very promising trend that this review identified is the coupling of MDO with rapid prototyping techniques. Overall, this new addition will bridge the gap between MDO and manufacturing, but at the same time, it will also provide further support to the design through the use of valuable testing data which are typically available only in the later stages of the process.

\subsection{A Roadmap for MDO of Aerial Vehicles}

4.2.1. General Overview. Having established the research gaps and trends, the next step of this review is to propose a roadmap of best practices and methods for applying MDO on aerial vehicle design (see Figure 9). The roadmap was developed after analyzing the findings of this review, and it should be considered as a collective summary of all the elements and actions that should be taken into account in a typical MDO case study. Hence, this is a further contribution of this work that is primarily and solely based on the state of the art which was previously presented, while in addition to this, the total process has also been enhanced with potentially critical elements that were identified during the investigation of the research gaps. The main objective here is to provide a generic tool that can be used to guide engineers in various design problems, and in this respect, the roadmap should be received as a flexible tool that can be adapted to a variety of research scenarios.

On the whole, the roadmap has been divided into three blocks (A, B, and C), which largely aim to describe who should be involved in the process, what elements are required, and which activities should be considered. Each element of the roadmap is a brief summary of the findings that were presented in the review of the state of the art, and therefore, the reader is encouraged to follow the logical connections back to each respective chapter in order to retrieve more information about the available solutions. The first block (A) is largely built upon the work that can be found in [39] as well as [84], and the aim is to present the roles of the people that are needed in each one of the considered stages of the process. The second block (B) is based on the findings of the review and shows the fundamental elements of a typical MDO workflow which are namely the definition 


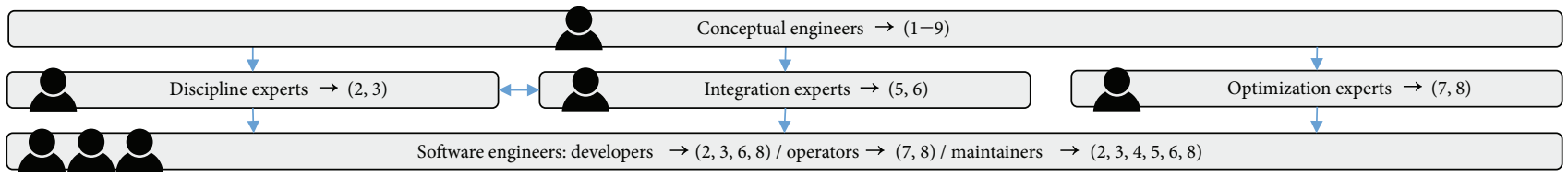

(a)

\begin{tabular}{|c|c|c|}
\hline Optimization requirements & Framework development & Optimization/data management \\
\hline Problem formulation & Level of fidelity & Optimization run(s) \\
\hline $\begin{array}{l}\text { Define the objectives and constraints } \\
\text { and decide on the design variables }\end{array}$ & $\begin{array}{l}\text { Verify that the fidelity level is sufficient } \\
\text { for the chosen development stage }\end{array}$ & $\begin{array}{l}\text { Choose a suitable algorithm and } \\
\text { start the analysis/optimization }\end{array}$ \\
\hline $\begin{array}{l}\text { Weight or performance objective for a } \\
\text { general overview. Airworthiness aspects } \\
\text { and safety regulations as constraints to } \\
\text { ensure realism. Basic airframe variables } \\
\text { for concept generation or higher order } \\
\text { parametrization for detail designs. }\end{array}$ & $\begin{array}{l}\text { Low and medium fidelity tools for fast } \\
\text { calculations at conceptual level. Higher } \\
\text { fidelity tools to increase confidence and } \\
\text { handle unconventional designs. Multifidelity } \\
\text { process to bring moredetail at a narrower } \\
\text { area of the design space. }\end{array}$ & $\begin{array}{l}\text { Design of experiments for sampling the } \\
\text { design space. Genetic algorithms for } \\
\text { problems with local optima or black-box } \\
\text { models. Gradient-based algorithms for } \\
\text { adjoint formulations or functions where } \\
\text { the derivatives can be easily calculated. }\end{array}$ \\
\hline Disciplinary models & Decomposition architectures & Decision support \\
\hline $\begin{array}{l}\text { Employ the disciplinary models that } \\
\text { are needed to capture the physics }\end{array}$ & $\begin{array}{l}\text { Establish an appropriate integration that } \\
\text { guarantees a feasible problem solution }\end{array}$ & $\begin{array}{l}\text { Validate the results and manage the } \\
\text { obtained data in a meaningful way }\end{array}$ \\
\hline $\begin{array}{l}\text { A standard foundation of common } \\
\text { aeronautical disciplines to measure the } \\
\text { performance. Further models to } \\
\text { quantify the case-specific requirements. } \\
\text { A link to the front and back end of the } \\
\text { process: marketand manufacturing. }\end{array}$ & $\begin{array}{l}\text { MDF for simple decoupling between } \\
\text { aerodynamics and structures. CO for } \\
\text { parallel computing and decomposition } \\
\text { of complex models (e.g., mission). } \\
\text { Asymmetric approaches for local } \\
\text { optimization of the on-board systems. }\end{array}$ & $\begin{array}{l}\text { Available data, high-fidelity simulations, } \\
\text { and physical experiments for validation. } \\
\text { Physical prototypes for quick subscale } \\
\text { testing. 2D graphs and SOM for simple } \\
\text { result visualization. Data management } \\
\text { tools for design space exploration. }\end{array}$ \\
\hline Analysis capabilities & Computational efficiency & Organizational integration \\
\hline $\begin{array}{l}\text { Develop analysis capabilities that } \\
\text { can enhance the calculations }\end{array}$ & $\begin{array}{l}\text { Implement solutions that can increase } \\
\text { the speed of the optimization }\end{array}$ & $\begin{array}{l}\text { Incorporate the optimization results into } \\
\text { the product development process }\end{array}$ \\
\hline $\begin{array}{l}\text { Aeroelastic and structural analyses to } \\
\text { increase the knowledge in detail design. } \\
\text { Nondeterministic approaches to } \\
\text { account for mission uncertainties. Flight } \\
\text { path planning and network allocation to } \\
\text { consider marketing. }\end{array}$ & $\begin{array}{l}\text { Metamodels to increase the range of } \\
\text { applications at a low computational } \\
\text { cost. Multiple metamodels (e.g., per } \\
\text { wing panel) to increase the prediction } \\
\text { accuracy. Parallel-distributed } \\
\text { calculations for more computer power. }\end{array}$ & $\begin{array}{l}\text { Reusable and user-friendly optimization } \\
\text { tools that can be intuitively used by the } \\
\text { decision makers. Multirole and } \\
\text { multi-cultural teams of experts rather } \\
\text { than conceptual engineers to ensure } \\
\text { the general success of the process. }\end{array}$ \\
\hline
\end{tabular}

(b)

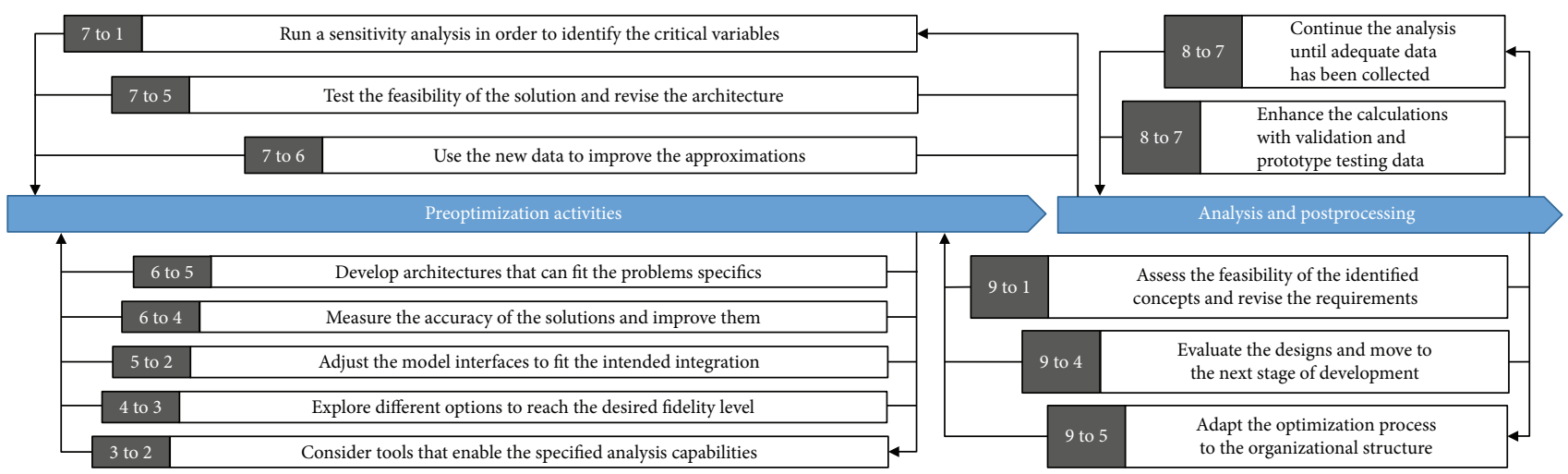

(c)

FIgURE 9: The proposed roadmap for MDO of aerial vehicles.

of the optimization requirements, the development of the framework, and the simulation and data management. Lastly, the third block (C) presents the logical flow of the activities in the process, and it is a personal contribution that aims to summarize the possible iterative feedbacks that can be taken into account during or at the end of the considered steps.

4.2.2. Block Analysis. Starting with block (A), it can be seen that the main working principle which is being introduced here is the simultaneous cooperation of three different groups of people. Compared to previous studies where the focus was solely divided on either the engineering [84] or the software responsibilities [39], this new layout combines expertise from three different fields and therefore ensures a more holistic approach to framework development. In general, the process is guided by the conceptual or design engineers since this group can translate the design requirements into MDO needs and in turn bridge the gap between the 
product development process and corresponding framework capabilities. Next are the various experts who are delegated with the task of applying their domain-specific knowledge and experience in order to perform specialized tasks and provide advanced competencies in areas such as the disciplinary models, the integration, and the optimization. Finally, the software engineers have the role of developing solutions that can then be seamlessly integrated in the existing data structure of the organization but they also get the crucial role of operation and maintenance since they are typically the most qualified to perform this type of tasks.

Block (B) is comprised of 9 subdivisions which correspond and briefly summarize the findings of each chapter that has been presented in this review. The aim here is to guide the user through a number of distinct steps that are usually taken into account in MDO and accordingly to standardize the process by ensuring the consideration of all the critical elements. First, for each one of those steps, a recommendation is given on top in the form of an instruction, and then a list of the most common alternatives that this review identified are provided right below in order to give an overview of the possible strategies. Due to space limitations, the strategies which are shown here are only a very small part of the previously presented review, and thus, in order to get further information, the reader is encouraged to trace the numbered items back to the state of the art which was presented in chapter 3 . Steps 1 to 3 are designated as "optimization requirements" because they either constitute the description of the problem or the building elements that the framework will be based upon. Steps 4 to 6 are about the development of the aforementioned framework, and more specifically, about the integration of the models and analysis capabilities through the use of decomposition architectures or efficient computing techniques. Lastly, steps 7 to 9 include the optimization as well as management of the results, and in particular, it is the point where the framework is simulated and the data are post processed so that they can be further used in the decision-making process.

Block (C) shows the dependencies of the process steps and the activities that the user should consider in order to improve the MDO framework. The problem here is that the development of a MDO framework is not a purely sequential process, but instead, it requires an iterative approach where a solution is first implemented and then it is tested so that it can be either approved or improved. To this end, various feedback activities were identified and they were added to the roadmap by using a simple logic where at the end of each step, the user is called to reflect on previous actions and then make the necessary changes. For example, the notation " 3 to 2 " indicates that at the end of step 3 , the user should go back and revise step 2 . The iterative activities can be with the same group of steps (e.g., 6 to 4 ) or between steps that are placed very far apart (e.g., 9 to 1 ), while the possible iterations within each step (e.g., 2 to 2: the trial and error process until a model is developed) have been omitted in order to reduce the complexity of the roadmap.

4.2.3. Future Work. Overall, it should be noted that the proposed roadmap is a first approach towards the modelling of the MDO process, and in this respect, it is clear that there is margin for improvement and limitations which can be eliminated through future modifications and expansions. First, it is worth elaborating further on the involved people and cultural adaptation of MDO which to this date was rather limited due to the lack of available research on this topic. Additionally, the 9 proposed steps could be individually improved by adding further state-of-the-art information which can be the result of a more in-depth or a more up-todate review on each one of the covered topics. Moreover, the suggested iterative activities could be described in more detail and enhanced with more quantitative data which can then be used to better estimate their effect towards the total process. Furthermore, there is a need to apply the roadmap on more specific case studies and in turn generate different versions which will generally be more suitable for use in the development of particular aircraft types. To sum up, it is of utmost importance to also investigate the applicability of the roadmap, and a very crucial part that is left as future work is to evaluate it against the current industrial practices and assess it in the context of actual product development scenarios.

\section{Conclusions}

This paper presents a review of the recent advancements in the field of multidisciplinary design optimization (MDO) and focuses on the particulars of its applicability in the development process of aerial vehicles. The main objective of this work is to present the problem from a broad perspective, and therefore, the emphasis here is not only limited to the practical features of the method but it also expands to the specifics of its use within the product development process. In total, the present literature sample is comprised of 105 case studies that come from both journal articles and conference papers, while the three types of contributions which are primarily considered here include practical applications, development of methodologies, and reviews.

The outcome of the review is given in a "state of the art" section and it is further organized in various subchapters that aim to summarize the current developments in respect to some basic fundamentals of the MDO process. The aforementioned thematic topics are organized in an order that resembles the typical workflow in MDO, and they are elaborated by first presenting general information as well as statistical analyses and then a description of the most common strategies as well as limitations. Based on this initial research, the paper continues by explicitly discussing the identified gaps and trends which are then grouped into three categories that cover the shortcomings in the framework elements, the problems with the optimization performance, and the issues with the integration of data in the development process.

Conclusively, this work presents a roadmap for implementing MDO in aerial vehicle design that considers the essential technical aspects of optimization but it also takes into account its integration within the organizational structure. The contribution is a compilation of the fundamental MDO features in an appropriate format which to this date has been a gap in the relevant literature, but at the same time it has also been largely sought after by both the academia and 
the industry. Overall, detailed instructions on how to use the roadmap and discussions on its limitations are herein provided, and it is shown that further work is required in order to maintain this very first version up to date and expand it to more applications.

\section{Conflicts of Interest}

The authors declare that they have no conflicts of interest.

\section{Acknowledgments}

The authors would like to acknowledge the financial support received from the Vinnova IMPOz project with reference number Dnr. 2013-03758.

\section{References}

[1] J. Sobieszczanski-Sobieski and R. T. Haftka, "Multidisciplinary aerospace design optimization: survey of recent developments," Structural Optimization, vol. 14, no. 1, pp. 1-23, 1997.

[2] S. Padula and R. Gillian, "Multidisciplinary environments: a history of engineering framework development," in 11th AIAA/ISSMO Multidisciplinary Analysis and Optimization Conference, Portsmouth, Virginia, USA, September 2006.

[3] Z. Wang, W. Huang, and L. Yan, "Multidisciplinary design optimization approach and its application to aerospace engineering," Chinese Science Bulletin, vol. 59, no. 36, pp. 53385353, 2014.

[4] F. A. C. Viana, T. W. Simpson, V. Balabanov, and V. Toropov, "Special section on multidisciplinary design optimization: metamodeling in multidisciplinary design optimization: how far have we really come?," AIAA Journal, vol. 52, no. 4, pp. 670-690, 2014.

[5] J. R. R. A. Martins and A. B. Lambe, "Multidisciplinary design optimization: a survey of architectures," AIAA Journal, vol. 51, no. 9, pp. 2049-2075, 2013.

[6] W. Yao, X. Chen, W. Luo, M. van Tooren, and J. Guo, "Review of uncertainty-based multidisciplinary design optimization methods for aerospace vehicles," Progress in Aerospace Sciences, vol. 47, no. 6, pp. 450-479, 2011.

[7] A. Salas and J. Townsend, "Framework requirements for MDO application development," in 7th AIAA/USAF/NASA/ ISSMO Symposium on Multidisciplinary Analysis and Optimization, Multidisciplinary Analysis Optimization Conferences, St. Louis, MO, USA, 1998.

[8] G. Belie, "Non-technical barriers to multidisciplinary optimization in the aerospace industry," in 9th AIAA/ISSMO Symposium on Multidisciplinary Analysis and Optimization, Multidisciplinary Analysis Optimization Conferences, Atlanta, Georgia, USA, September 2002.

[9] J. Giesing and J. F. Barthelemy, "A summary of industry MDO applications and needs," in 7th AIAA/USAF/NASA/ ISSMO Symposium on Multidisciplinary Analysis and Optimization, Multidisciplinary Analysis Optimization Conferences, St. Louis, MO, USA, 1998.

[10] T. W. Simpson and J. R. R. A. Martins, "Multidisciplinary design optimization for complex engineered systems: report from a National Science Foundation workshop," Journal of Mechanical Design, vol. 133, no. 10, article 101002, 2011.
[11] J. Agte, O. de Weck, J. Sobieszczanski-Sobieski, P. Arendsen, A. Morris, and M. Spieck, "MDO: assessment and direction for advancement-an opinion of one international group," Structural and Multidisciplinary Optimization, vol. 40, no. 1-6, pp. 17-33, 2009.

[12] D. Allison, C. Morris, J. Schetz et al., "A multidisciplinary design optimization framework for design studies of an efficient supersonic air vehicle," in 12th AIAA Aviation Technology, Integration, and Operations (ATIO) Conference and 14th AIAA/ISSMO Multidisciplinary Analysis and Optimization Conference, Aviation Technology, Integration, and Operations (ATIO) Conferences, Indianapolis, IN, USA, September 2012.

[13] W. Hurwitz, S. Donovan, J. Camberos, and B. German, "A systems engineering approach to the application of multidisciplinary design, analysis and optimization (MDAO) for efficient supersonic air-vehicle exploration (ESAVE)," in 12th AIAA Aviation Technology, Integration, and Operations (ATIO) Conference and 14th AIAA/ISSMO Multidisciplinary Analysis and Optimization Conference, Aviation Technology, Integration, and Operations (ATIO) Conferences, Indianapolis, IN, USA, September 2012.

[14] S. S. Ghoman, R. K. Kapania, P. C. Chen, D. Sarhaddi, and D. H. Lee, "Multifidelity, multistrategy, and multidisciplinary design optimization environment," Journal of Aircraft, vol. 49, no. 5, pp. 1255-1270, 2012.

[15] B. Morrisey and R. McDonald, "Multidisciplinary design optimization of an extreme aspect ratio HALE UAV," in 9th AIAA Aviation Technology, Integration, and Operations Conference (ATIO), Aviation Technology, Integration, and Operations (ATIO) Conferences, Hilton Head, SC, USA, September 2009.

[16] O. Gur, M. Bhatia, W. H. Mason, J. A. Schetz, R. K. Kapania, and T. Nam, "Development of a framework for truss-braced wing conceptual MDO," Structural and Multidisciplinary Optimization, vol. 44, no. 2, pp. 277-298, 2011.

[17] S. K. Rallabhandi and D. N. Mavris, "Simultaneous airframe and propulsion cycle optimization for supersonic aircraft design," Journal of Aircraft, vol. 45, no. 1, pp. 38-55, 2008.

[18] R. A. Reuter, S. Iden, R. D. Snyder, and D. L. Allison, “An overview of the optimized integrated multidisciplinary systems program," in 57th AIAA/ASCE/AHS/ASC Structures, Structural Dynamics, and Materials Conference, AIAA SciTech Forum, (AIAA 2016-0674), San Diego, CA, USA, 2016.

[19] L. Jaeger, C. Gogu, S. Segonds, and C. Bes, “Aircraft multidisciplinary design optimization under both model and design variables uncertainty," Journal of Aircraft, vol. 50, no. 2, pp. 528-538, 2013.

[20] P. Cassidy, T. Gatzke, and C. Vaporean, "Integrating synthesis and simulation for conceptual design," in 46th AIAA Aerospace Sciences Meeting and Exhibit, Aerospace Sciences Meetings, Reno, NV, USA, January 2008.

[21] N. V. Nguyen, J. W. Lee, Y. D. Lee, and H. U. Park, "A multidisciplinary robust optimisation framework for UAV conceptual design," The Aeronautical Journal, vol. 118, no. 1200, pp. 123-142, 2014.

[22] S. Dufresne, C. Johnson, and D. N. Mavris, "Variable fidelity conceptual design environment for revolutionary unmanned aerial vehicles," Journal of Aircraft, vol. 45, no. 4, pp. 14051418, 2008.

[23] M. Sadraey, "A systematic approach in aircraft configuration design optimization," in The 26th Congress of ICAS and 8th AIAA ATIO, Aviation Technology, Integration, 
and Operations (ATIO) Conferences, Anchorage, Alaska, September 2008.

[24] D. Bianchi, T. H. Orra, and P. Paglione, "Monte Carlo based Robust MDO applied to aircraft conceptual design: a technical-financial coupling optimization strategy," in 15th AIAA Aviation Technology, Integration, and Operations Conference, AIAA AVIATION Forum, (AIAA 2015-2737), Dallas, TX, USA, 2015.

[25] J. Yoon, N. Nguyen, S.-M. Choi, J.-W. Lee, S. Kim, and Y.-H. Byun, "Multidisciplinary general aviation aircraft design optimizations incorporating airworthiness constraints," in 10th AIAA Aviation Technology, Integration, and Operations (ATIO) Conference, Aviation Technology, Integration, and Operations (ATIO) Conferences, Fort Worth, TX, USA, September 2010.

[26] T. W. Lukaczyk, A. D. Wendorff, M. Colonno et al., "SUAVE: an open-source environment for multi-fidelity conceptual vehicle design," in 16th AIAA/ISSMO Multidisciplinary Analysis and Optimization Conference, AIAA AVIATION Forum, (AIAA 2015-3087), Dallas, TX, USA, 2015.

[27] S. Dean, J. Doherty, and T. Wallace, "MDO-based concept modelling and the impact of fuel systems on wing design," in 47th AIAA Aerospace Sciences Meeting including The New Horizons Forum and Aerospace Exposition, Aerospace Sciences Meetings, Orlando, FL, USA, January 2009.

[28] R. E. Perez, H. H. T. Liu, and K. Behdinan, "Multidisciplinary optimization framework for control-configuration integration in aircraft conceptual design," Journal of Aircraft, vol. 43, no. 6, pp. 1937-1948, 2006.

[29] C. Morris, D. Allison, C. Sultan, J. Schetz, and R. Kapania, "Towards flying qualities constraints in the multidisciplinary design optimization of a supersonic tailless aircraft," in 12th AIAA Aviation Technology, Integration, and Operations (ATIO) Conference and 14th AIAA/ISSMO Multidisciplinary Analysis and Optimization Conference, Aviation Technology, Integration, and Operations (ATIO) Conferences, Indianapolis, IN, USA, September 2012.

[30] S. Choi, J. J. Alonso, and I. M. Kroo, "Two-level multifidelity design optimization studies for supersonic jets," Journal of Aircraft, vol. 46, no. 3, pp. 776-790, 2009.

[31] R. Ganguli and S. Rajagopal, "Multidisciplinary design optimization of an UAV wing using Kriging based multiobjective genetic algorithm," in 50th AIAA/ASME/ASCE/ AHS/ASC Structures, Structural Dynamics, and Materials Conference, Structures, Structural Dynamics, and Materials and Co-located Conferences, Palm Springs, CA, USA, May 2009.

[32] A. Gazaix, P. Gendre, E. Chaput et al., "Investigation of multi-disciplinary optimisation for aircraft preliminary design," in SAE 2011 AeroTech Congress \& Exhibition, Toulouse, France, 2011.

[33] D. D. Smith, A. T. Isikveren, R. M. Ajaj, and M. I. Friswell, "Multidisciplinary design optimization of an active nonplanar polymorphing wing," in 27th International Congress of the Aeronautical Sciences, Nice, France, 2010.

[34] A. Ceruti, G. Caligiana, and F. Persiani, "Comparative evaluation of different optimization methodologies for the design of UAVs having shape obtained by hot wire cutting techniques," International Journal on Interactive Design and Manufacturing (IJIDeM), vol. 7, no. 2, pp. 63-78, 2012.

[35] J. Brezillon, A. Ronzheimer, D. Haar et al., "Development and application of multi-disciplinary optimization capabilities based on high-fidelity methods," in 53rd AIAA/ASME/ ASCE/AHS/ASC Structures, Structural Dynamics and Materials Conference, Structures, Structural Dynamics, and Materials and Co-located Conferences, Honolulu, Hawaii, April 2012.

[36] N. Kroll, M. Abu-Zurayk, D. Dimitrov et al., "DLR project Digital-X: towards virtual aircraft design and flight testing based on high-fidelity methods," CEAS Aeronautical Journal, vol. 7, no. 1, pp. 3-27, 2015.

[37] N.-V. Nguyen, S.-M. Choi, W.-S. Kim et al., "Multidisciplinary unmanned combat air vehicle system design using multifidelity model," Aerospace Science and Technology, vol. 26, no. 1, pp. 200-210, 2013.

[38] R. P. Henderson, J. R. R. A. Martins, and R. E. Perez, "Aircraft conceptual design for optimal environmental performance," The Aeronautical Journal, vol. 116, no. 1175, pp. 1-22, 2012.

[39] J. P. T. J. Berends, M. J. L. Tooren, and D. N. V. Belo, “A distributed multi-disciplinary optimisation of a blended wing body UAV using a multi-agent task environment," in 47 th AIAA/ASME/ASCE/AHS/ASC Structures, Structural Dynamics, and Materials Conference, Structures, Structural Dynamics, and Materials and Co-located Conferences, Newport, RI, USA, May 2006.

[40] L. Iqbal and J. Sullivan, "Multidisciplinary design and optimization (MDO) methodology for the aircraft conceptual design," in 50th AIAA Aerospace Sciences Meeting including the New Horizons Forum and Aerospace Exposition, Aerospace Sciences Meetings, Nashville, TN, USA, January 2012.

[41] S. Choi, J. J. Alonso, I. M. Kroo, and M. Wintzer, "Multifidelity design optimization of low-boom supersonic jets," Journal of Aircraft, vol. 45, no. 1, pp. 106-118, 2008.

[42] P. W. Jansen and R. E. Perez, "Coupled optimization of aircraft design and fleet allocation with uncertain passenger demand," in 2013 Aviation Technology, Integration, and Operations Conference, AIAA AVIATION Forum, (AIAA 2013-4392), Los Angeles, CA, USA, 2013.

[43] E. Alyanak, R. Kolonay, P. Flick, N. Lindsley, and S. Burton, "Efficient supersonic air vehicle preliminary conceptual multi-disciplinary design optimization results," in 12th AIAA Aviation Technology, Integration, and Operations (ATIO) Conference and 14th AIAA/ISSMO Multidisciplinary Analysis and Optimization Conference, Aviation Technology, Integration, and Operations (ATIO) Conferences, Indianapolis, IN, USA, September 2012.

[44] A. Deblois and M. Abdo, "Multi-fidelity multidisciplinary design optimization of metallic and composite regional and business jets," in 13th AIAA/ISSMO Multidisciplinary Analysis Optimization Conference, Multidisciplinary Analysis Optimization Conferences, Fort Worth, TX, USA, September 2010.

[45] M. Laban and U. Herrmann, "Multi-disciplinary analysis and optimisation applied to supersonic aircraft part 1: analysis tools," in 48th AIAA/ASME/ASCE/AHS/ASC Structures, Structural Dynamics, and Materials Conference, Structures, Structural Dynamics, and Materials and Co-located Conferences, Honolulu, Hawaii, April 2007.

[46] P. Piperni, A. DeBlois, and R. Henderson, "Development of a multilevel multidisciplinary-optimization capability for an industrial environment," AIAA Journal, vol. 51, no. 10, pp. 2335-2352, 2013.

[47] C. Pak, "Aeroelastic tailoring study of an N+2 Lowboom supersonic commercial transport aircraft," in 16th 
AIAA/ISSMO Multidisciplinary Analysis and Optimization Conference, AIAA AVIATION Forum, (AIAA 2015-2791), Dallas, TX, USA, 2015.

[48] Q. Liu, S. B. Mulani, and R. K. Kapania, "Global/local multidisciplinary design optimization of subsonic wing," in 10th AIAA Multidisciplinary Design Optimization Conference, AIAA SciTech Forum, (AIAA 2014-0471), National Harbor, MD, USA, 2014

[49] S. Guo, D. Li, and Y. Liu, "Multi-objective optimization of a composite wing subject to strength and aeroelastic constraints," Proceedings of the Institution of Mechanical Engineers, Part G: Journal of Aerospace Engineering, vol. 226, no. 9, pp. 1095-1106, 2011.

[50] N. V. Nguyen, J.-W. Lee, M. Tyan, and D. Lee, "Possibilitybased multidisciplinary optimisation for electric-powered unmanned aerial vehicle design," The Aeronautical Journal, vol. 119, no. 1221, pp. 1397-1414, 2015.

[51] C. Davies, M. Stelmack, P. S. Zink, A. De La Garza, and P. Flick, "High fidelity MDO process development and application to fighter strike conceptual design," in 12th AIAA Aviation Technology, Integration, and Operations (ATIO) Conference and 14th AIAA/ISSMO Multidisciplinary Analysis and Optimization Conference, Aviation Technology, Integration, and Operations (ATIO) Conferences, Indianapolis, IN, USA, September 2012.

[52] A. Suleman, F. Lau, J. Vale, and F. Afonso, "Multidisciplinary performance based optimization of morphing aircraft," in 22nd AIAA/ASME/AHS Adaptive Structures Conference, AIAA SciTech Forum, (AIAA 2014-0761), National Harbor, MD, USA, 2014.

[53] R. Navaratne and J. Murugaiyan, "Multi disciplinary optimization of flight trajectories," in 2012 IEEE Aerospace Conference, pp. 1-15, Big Sky, MT, USA, March 2012.

[54] B. Yan, P. Jansen, and R. Perez, "Multidisciplinary design optimization of airframe and trajectory considering cost, noise, and fuel burn," in 12th AIAA Aviation Technology, Integration, and Operations (ATIO) Conference and 14th AIAA/ISSMO Multidisciplinary Analysis and Optimization Conference, Aviation Technology, Integration, and Operations (ATIO) Conferences, Indianapolis, IN, USA, September 2012.

[55] J. Longo, M. Sippel, G. Carrier, A. Loubeau, R. Jarlas, and D. Perigo, "Concept study for a Mach 6 transport aircraft," in 47th AIAA Aerospace Sciences Meeting including The New Horizons Forum and Aerospace Exposition, Aerospace Sciences Meetings, Orlando, FL, USA, January 2009.

[56] R. Perez and J. Martins, "pyACDT: an object-oriented framework for aircraft design modelling and multidisciplinary optimization," in 12th AIAA/ISSMO Multidisciplinary Analysis and Optimization Conference, Multidisciplinary Analysis Optimization Conferences, Victoria, BC, Canada, September 2008.

[57] K. Amadori, C. Jouannet, and P. Krus, "A framework for aerodynamic and structural optimization in conceptual design," in 25th AIAA Applied Aerodynamics Conference, Fluid Dynamics and Co-located Conferences, Miami, FL, USA, June 2007.

[58] K. Geiselhart, L. Ozoroski, J. Fenbert, E. Shields, and W. Li, "Integration of multifidelity multidisciplinary computer codes for design and analysis of supersonic aircraft," in 49th AIAA Aerospace Sciences Meeting including the New Horizons Forum and Aerospace Exposition, Aerospace Sciences Meetings, Orlando, FL, USA, January 2011.
[59] T. Zhang, Z. Wang, W. Huang, and L. Yan, "Parameterization and optimization of hypersonic-gliding vehicle configurations during conceptual design," Aerospace Science and Technology, vol. 58, pp. 225-234, 2016.

[60] F. Daoud, S. Deinert, R. Maierl, and Ö. Petersson, "Integrated multidisciplinary aircraft design process supported by a decentral MDO framework," in 16th AIAA/ISSMO Multidisciplinary Analysis and Optimization Conference, AIAA AVIATION Forum, (AIAA 2015-3090), Dallas, TX, USA, 2015.

[61] K. Alston, S. Doyle, T. Winter, H. Kim, and S. Ragon, "High fidelity multidisciplinary optimization (HFMDO)," in 13th AIAA/ISSMO Multidisciplinary Analysis Optimization Conference, Multidisciplinary Analysis Optimization Conferences, Fort Worth, TX, USA, September 2010.

[62] A. Morris, C. Allen, and T. Rendall, "Wing Design by Aerodynamic and Aeroelastic Shape Optimisation," in 26th AIAA Applied Aerodynamics Conference, Guidance, Navigation, and Control and Co-located Conferences, Honolulu, Hawaii, August 2008.

[63] L. Cavagna, S. Ricci, and L. Travaglini, "NeoCASS: an integrated tool for structural sizing, aeroelastic analysis and MDO at conceptual design level," Progress in Aerospace Sciences, vol. 47, no. 8, pp. 621-635, 2011.

[64] L. Travaglini, S. Ricci, and G. Bindolino, "PyPAD: a multidisciplinary framework for preliminary airframe design," Aircraft Engineering and Aerospace Technology, vol. 88, no. 5, pp. 649-664, 2016.

[65] S. Ricci and M. Terraneo, "Application of MDO techniques to the preliminary design of morphed aircraft," in 11th AIAA/ ISSMO Multidisciplinary Analysis and Optimization Conference, Multidisciplinary Analysis Optimization Conferences, Portsmouth, VA, USA, September 2006.

[66] F. Daoud, O. Petersson, S. Deinert, and P. Bronny, "Multidisciplinary airframe design process: incorporation of steady and unsteady aeroelastic loads," in 12th AIAA Aviation Technology, Integration, and Operations (ATIO) Conference and 14th AIAA/ISSMO Multidisciplinary Analysis and Optimization Conference, Aviation Technology, Integration, and Operations (ATIO) Conferences, Indianapolis, IN, USA, September 2012.

[67] L. Versiani Cabral, P. Paglione, and B. Silva de Mattos, "Multi-objective design optimization framework for conceptual design of families of aircraft," in 44th AIAA Aerospace Sciences Meeting and Exhibit, Aerospace Sciences Meetings, Reno, NV, USA, January 2006.

[68] K. Reynolds and N. Nguyen, "Multi-objective wing shape optimization of an elastically-shaped aircraft concept," in 51st AIAA Aerospace Sciences Meeting including the New Horizons Forum and Aerospace Exposition, Aerospace Sciences Meetings, Grapevine (Dallas/Ft. Worth Region), TX, USA, January 2013.

[69] K. S. Jeon, J. W. Lee, Y. H. Byun, and Y. H. Yu, "Multidisciplinary UCAV system design and optimization using repetitive response surface enhancement technique," in 48th AIAA/ASME/ASCE/AHS/ASC Structures, Structural Dynamics, and Materials Conference, Structures, Structural Dynamics, and Materials and Co-located Conferences, Honolulu, Hawaii, 2007.

[70] A. A. Mirzoyan, "Studies on MDO of engine design parameters with mission, noise and emission criteria at SSBJ engine conceptual design," in 26th International Congress of the Aeronautical Sciences, Anchorage, AK, USA, 2008. 
[71] S. V. Subramanian and D. A. DeLaurentis, "Application of multidisciplinary systems-of-systems optimization to an aircraft design problem," Systems Engineering, vol. 19, no. 3, pp. 235-251, 2016.

[72] Y. Deremaux, N. Pietremont, J. Negrier, E. Herbin, and M. Ravachol, "Environmental MDO and uncertainty hybrid approach applied to a supersonic business jet," in 12th AIAA/ISSMO Multidisciplinary Analysis and Optimization Conference, Multidisciplinary Analysis Optimization Conferences, Victoria, BC, Canada, September 2008.

[73] U. Iemma and M. Diez, "Optimal conceptual design of aircraft including community noise prediction," in 12th AIAA/ CEAS Aeroacoustics Conference (27th AIAA Aeroacoustics Conference), Aeroacoustics Conferences, Cambridge, MA, USA, May 2006.

[74] C. Werner-Westphal, W. Heinze, and P. Horst, "Multidisciplinary integrated preliminary design applied to unconventional aircraft configurations," Journal of Aircraft, vol. 45, no. 2, pp. 581-590, 2008.

[75] S. Haghighat, J. R. R. A. Martins, and H. H. T. Liu, "Aeroservoelastic design optimization of a flexible wing," Journal of Aircraft, vol. 49, no. 2, pp. 432-443, 2012.

[76] C. Jouannet and P. Krus, "Direct simulation based optimization for aircraft design including systems," in 11th AIAA/ ISSMO Multidisciplinary Analysis and Optimization Conference, Multidisciplinary Analysis Optimization Conferences, Portsmouth, VA, USA, September 2006.

[77] A. Ning and I. Kroo, "Multidisciplinary considerations in the design of wings and wing tip devices," Journal of Aircraft, vol. 47, no. 2, pp. 534-543, 2010.

[78] C. M. Meckstroth and W. B. Blake, "Control focused multidisciplinary design optimization of tailless fighter aircraft," in 16th AIAA/ISSMO Multidisciplinary Analysis and Optimization Conference, AIAA AVIATION Forum, (AIAA 20152324), Dallas, TX, USA, 2015.

[79] P. Piperni, M. Abdo, F. Kafyeke, and A. T. Isikveren, "Preliminary aerostructural optimization of a large business jet," Journal of Aircraft, vol. 44, no. 5, pp. 1422-1438, 2007.

[80] N. Davendraingam and W. Crossley, "Robust optimization of aircraft design and airline network design incorporating econometric trends," in 11th AIAA Aviation Technology, Integration, and Operations (ATIO) Conference, Aviation Technology, Integration, and Operations (ATIO) Conferences, Virginia Beach, VA, USA, September 2011.

[81] R. E. Peoples and K. E. Willcox, "Value-based multidisciplinary optimization for commercial aircraft design and business risk assessment," Journal of Aircraft, vol. 43, no. 4, pp. 913921, 2006.

[82] P. S. Prakasha, P. D. Ciampa, L. Boggero, and M. Fioriti, "Assessment of airframe-subsystems synergy on overall aircraft performance in a collaborative design," in 17th AIAA/ISSMO Multidisciplinary Analysis and Optimization Conference, AIAA AVIATION Forum, (AIAA 2016-3667), Washington, D.C, USA, 2016.

[83] E. Safavi, M. Chaitanya, J. Ölvander, and P. Krus, "Multidisciplinary optimization of aircraft actuation system for conceptual analysis," in 51st AIAA Aerospace Sciences Meeting including the New Horizons Forum and Aerospace Exposition, Aerospace Sciences Meetings, Grapevine (Dallas/Ft. Worth Region), TX, USA, January 2013.

[84] E. Safavi, M. Tarkian, H. Gavel, and J. Olvander, "Collaborative multidisciplinary design optimization: a framework applied on aircraft conceptual system design," Concurrent Engineering, vol. 23, no. 3, pp. 236-249, 2015.

[85] A. Tfaily, K. Huynh, P. Piperni, and S. Liscouet-Hanke, "Landing gear integration in an industrial multi-disciplinary optimization environment," in SAE AeroTech Congress \& Exhibition, Montreal, Canada, 2013.

[86] J. Neidhoefer, J. Ryan, B. Leahy, and V. Tripp, “Cooperative multi-disciplinary design of integral load bearing antennas in small UAVs," in 47th AIAA Aerospace Sciences Meeting including The New Horizons Forum and Aerospace Exposition, Aerospace Sciences Meetings, Orlando, FL, USA, January 2009.

[87] D. Lee, L. F. Gonzalez, K. Srinivas, D. Auld, and J. Periaux, "Multi-objective / multidisciplinary design optimisation of blended wing body UAV via advanced evolutionary algorithms," in 45th AIAA Aerospace Sciences Meeting and Exhibit, Aerospace Sciences Meetings, Reno, NV, USA, January 2007.

[88] T. Zill, P. D. Ciampa, and B. Nagel, "A collaborative MDO approach for the flexible aircraft," in 54th AIAA/ASME/ ASCE/AHS/ASC Structures, Structural Dynamics, and Materials Conference, Structures, Structural Dynamics, and Materials and Co-located Conferences, (AIAA 2013-1677), 2013.

[89] P. W. Jansen, R. E. Perez, and J. R. R. A. Martins, "Aerostructural optimization of nonplanar lifting surfaces," Journal of Aircraft, vol. 47, no. 5, pp. 1490-1503, 2010.

[90] K.-S. Zhang, Z.-H. Han, W.-J. Li, and W.-P. Song, "Coupled aerodynamic/structural optimization of a subsonic transport wing using a surrogate model," Journal of Aircraft, vol. 45, no. 6, pp. 2167-2171, 2008.

[91] T. Long, L. Liu, S. Zhou, J. Wang, and L. Meng, "Multi-objective multidisciplinary optimization of long-endurance UAV wing using surrogate model in model center," in 12th AIAA/ISSMO Multidisciplinary Analysis and Optimization Conference, Multidisciplinary Analysis Optimization Conferences, Victoria, BC, Canada, September 2008.

[92] P. Gamboa, J. Vale, P. F. J. Lau, and A. Suleman, "Optimization of a morphing wing based on coupled aerodynamic and structural constraints," AIAA Journal, vol. 47, no. 9, pp. 2087-2104, 2009.

[93] G. Kenway and J. R. Martins, "Multipoint high-fidelity aerostructural optimization of a transport aircraft configuration," Journal of Aircraft, vol. 51, no. 1, pp. 144-160, 2014.

[94] R. P. Liem, G. K. W. Kenway, and J. R. R. A. Martins, "Multimission aircraft fuel-burn minimization via multipoint aerostructural optimization," AIAA Journal, vol. 53, no. 1, pp. 104-122, 2015.

[95] T. Kumano, S. Jeong, S. Obayashi, Y. Ito, K. Hatanaka, and H. Morino, "Multidisciplinary design optimization of wing shape for a small jet aircraft using Kriging model," in 44th AIAA Aerospace Sciences Meeting and Exhibit, Aerospace Sciences Meetings, Reno, NV, USA, January 2006.

[96] P. D. Ciampa, T. Zill, and B. Nagel, "Aeroelastic design and optimization of unconventional aircraft configurations in a distributed design environment," in 53rd AIAA/ASME/ ASCE/AHS/ASC Structures, Structural Dynamics and Materials Conference, Structures, Structural Dynamics, and Materials and Co-located Conferences, Honolulu, Hawaii, April 2012.

[97] M. J. Muir, E. J. Kolb, A. T. Parkinson et al., "The use of MDO and advanced manufacturing to demonstrate rapid, agile construction of a mission optimized UAV," in 54th AIAA/ ASME/ASCE/AHS/ASC Structures, Structural Dynamics, and Materials Conference, Structures, Structural Dynamics, 
and Materials and Co-located Conferences, (AIAA 20131675), Boston, MA, USA, 2013.

[98] G.-J. Park, T.-H. Lee, K. H. Lee, and K.-H. Hwang, "Robust design: an overview," AIAA Journal, vol. 44, no. 1, pp. 181191, 2006.

[99] M. J. Daskilewicz, B. J. German, T. T. Takahashi, S. Donovan, and A. Shajanian, "Effects of disciplinary uncertainty on multi-objective optimization in aircraft conceptual design," Structural and Multidisciplinary Optimization, vol. 44, no. 6, pp. 831-846, 2011.

[100] D. Neufeld, N. Nhu-Van, J.-W. Lee, and S. Kim, "A multidisciplinary possibilistic approach to light aircraft conceptual design," in 53rd AIAA/ASME/ASCE/AHS/ASC Structures, Structural Dynamics and Materials Conference, Structures, Structural Dynamics, and Materials and Co-located Conferences, Honolulu, Hawaii, April 2012.

[101] D. Neufeld, J. Chung, and K. Behdinian, "Aircraft conceptual design optimization considering fidelity uncertainties," Journal of Aircraft, vol. 48, no. 5, pp. 1602-1612, 2011.

[102] M. Tyan, N. V. Nguyen, S. Kim, and J.-W. Lee, "Database adaptive fuzzy membership function generation for possibilitybased aircraft design optimization," Journal of Aircraft, vol. 54, no. 1, pp. 114-124, 2017.

[103] S. Lehner, L. Lurati, G. Bower et al., "Advanced multidisciplinary optimization techniques for efficient subsonic aircraft design," in 48th AIAA Aerospace Sciences Meeting Including the New Horizons Forum and Aerospace Exposition, Aerospace Sciences Meetings, Orlando, FL, USA, January 2010.

[104] J. Allison, B. Roth, M. Kokkolaras, I. Kroo, and P. Papalambros, "Aircraft family Design using decomposition-based methods," in 11th AIAA/ISSMO Multidisciplinary Analysis and Optimization Conference, Multidisciplinary Analysis Optimization Conferences, Portsmouth, VA, USA, September 2006.

[105] S. K. Moon, K. J. Park, and T. W. Simpson, "Platform design variable identification for a product family using multiobjective particle swarm optimization," Research in Engineering Design, vol. 25, no. 2, pp. 95-108, 2013.

[106] R. D. Falck, J. S. Gray, and B. Naylor, "Parallel aircraft trajectory optimization with analytic derivatives," in 17th AIAA/ ISSMO Multidisciplinary Analysis and Optimization Conference, AIAA AVIATION Forum, (AIAA 2016-3207), Washington, D.C., USA, 2016.

[107] M. Mane, W. A. Crossley, and A. Nusawardhana, "System-ofsystems inspired aircraft sizing and airline resource allocation via decomposition," Journal of Aircraft, vol. 44, no. 4, pp. 1222-1235, 2007.

[108] C. Taylor and O. de Weck, "Coupled vehicle design and network flow optimization for air transportation systems," Journal of Aircraft, vol. 44, no. 5, pp. 1479-1486, 2007.

[109] N. V. Nguyen, M. Tyan, and J.-W. Lee, "A modified variable complexity modeling for efficient multidisciplinary aircraft conceptual design," Optimization and Engineering, vol. 16, no. 2, pp. 483-505, 2015.

[110] D. Bryson, B. Stanford, A. McClung et al., "Multidisciplinary optimization of a hovering wing with a service-oriented framework and experimental model validation," in 49th AIAA Aerospace Sciences Meeting including the New Horizons Forum and Aerospace Exposition, Aerospace Sciences Meetings, Orlando, FL, USA, January 2011.

[111] A. Iwaniuk, W. Wiśniowski, and J. Żółtak, "Multi-disciplinary optimisation approach for a light turboprop aircraft- engine integration and improvement," Aircraft Engineering and Aerospace Technology, vol. 88, no. 2, pp. 348-355, 2016.

[112] T. Zill, D. Böhnke, and B. Nagel, "Preliminary aircraft design in a collaborative multidisciplinary design environment," in 11th AIAA Aviation Technology, Integration, and Operations (ATIO) Conference, Aviation Technology, Integration, and Operations (ATIO) Conferences, Virginia Beach, VA, USA, September 2011.

[113] S. Ziemer, M. Glas, and G. Stenz, "A conceptual design tool for multi-disciplinary aircraft design," in 2011 Aerospace Conference, pp. 1-13, Big Sky, MT, USA, March 2011.

[114] T. Lefebvre, P. Schmollgruber, C. Blondeau, and G. Carrier, "Aircraft conceptual design in a multi-level, multi-fidelity, multi-disciplinary optimization process," in 28th International Congress of The Aeronautical Sciences, Brisbane, Australia, 2012.

[115] C. M. Liersch and M. Hepperle, "A distributed toolbox for multidisciplinary preliminary aircraft design," CEAS Aeronautical Journal, vol. 2, no. 1-4, pp. 57-68, 2011.

[116] K. Amadori, D. Lundström, and P. Krus, "Automated design and fabrication of micro-air vehicles," Proceedings of the Institution of Mechanical Engineers, Part G: Journal of Aerospace Engineering, vol. 226, no. 10, pp. 1271-1282, 2011.

[117] NASA Glenn Research Center, "openMDAO:an open-source MDAO framework written in Python," December 2017, http://openmdao.org/.

[118] Dassault Systemes, "Isight \& the SIMULIA execution engine," December 2017, https://www.3ds.com/productsservices/simulia/products/isight-simulia-execution-engine/ latest-release/.

[119] Phoenix Integration, "ModelCenter Integrate," December 2017, https://www.phoenix-int.com/product/modelcenterintegrate/.

[120] PIDOTECH, "PIAnO: process integration automation and optimization," December 2017, http://www.pidotech.com/ en/product/PIAnO.aspx.

[121] ESTECO, "modeFRONTIER: process automation and optimization in the engineering design process," December 2017, https://www.esteco.com/modefrontier.

[122] T. Melin, "Tornado: a vortex lattice method implemented in MATLAB," December 2017, http://tornado.redhammer.se/.

[123] D. Raymer, Aircraft Design : A Conceptual Approach, American Institute of Aeronautics \& Astronautics, 2013.

[124] E. Torenbeek, Advanced Aircraft Design: Conceptual Design, Technology and Optimization of Subsonic Civil Airplanes, John Wiley \& Sons, 2013.

[125] T. Megson, Aircraft Structures for Engineering Students, Butterworth-Heinemann, 2016.

[126] A. El-Sayed, Aircraft Propulsion and Gas Turbine Engines, CRC Press, Boca Raton, FL, USA, 2nd edition, 2008.

[127] SIEMENS, "NX NASTRAN: the premier FEA solver for structural simulation," December 2017, https://www.plm. automation.siemens.com/en/products/simcenter/nastran/.

[128] ANSYS, "Fluent," December 2017, http://www.ansys.com/ Products/Fluids/ANSYS-Fluent.

[129] Southwest Research Institute, "NPSS: numerical propulsion system simulation,” December 2017, https://www.swri.org/ consortia/numerical-propulsion-system-simulation-npss.

[130] NASA Software, "FLOPS: flight optimization system," December 2017, https://software.nasa.gov/software/LAR18934-1. 


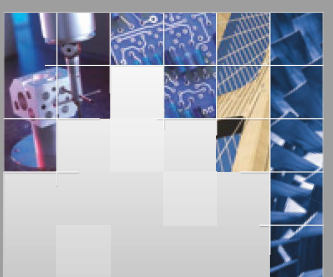

\section{Enfincering}
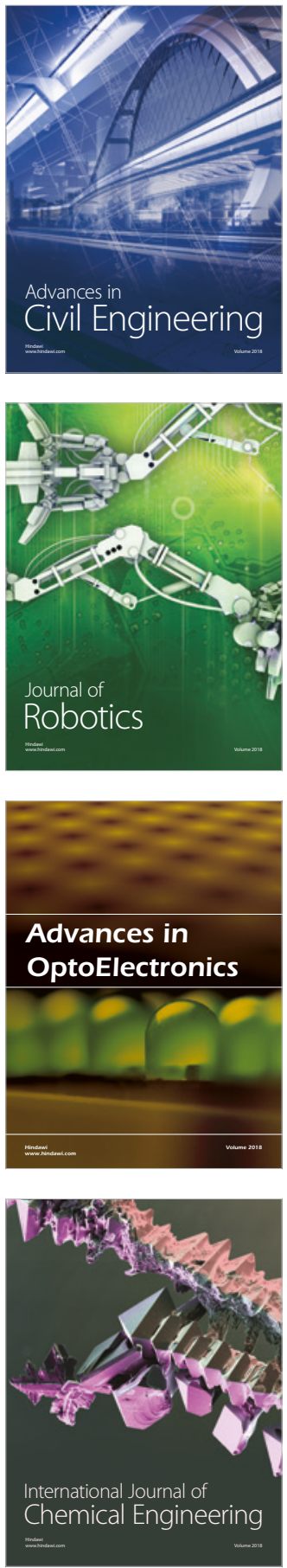

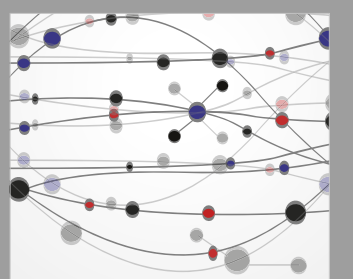

\section{Rotating \\ Machinery}

The Scientific World Journal

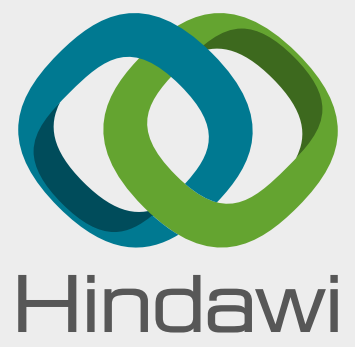

Submit your manuscripts at

www.hindawi.com
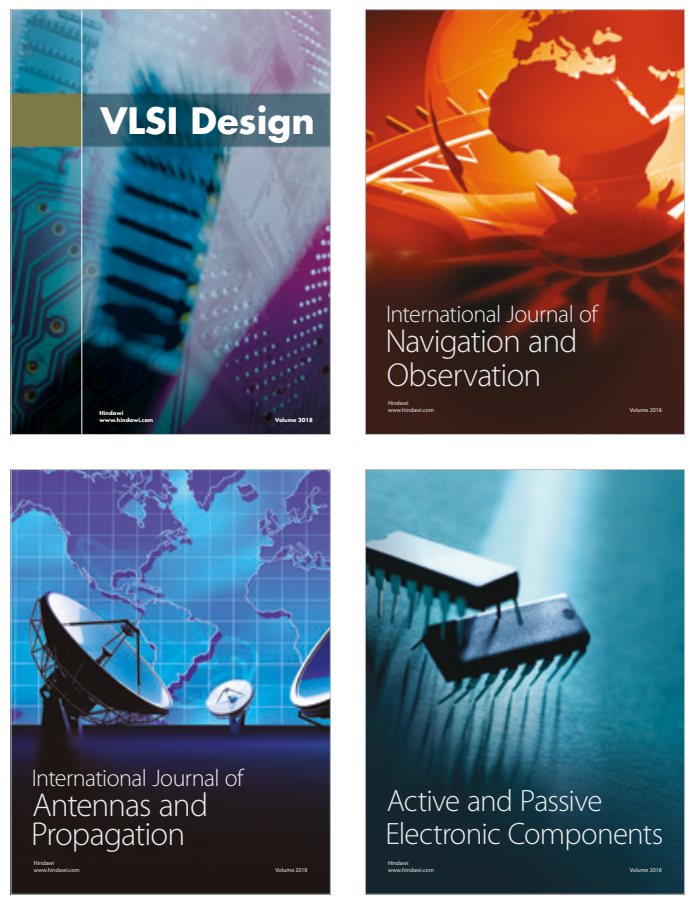
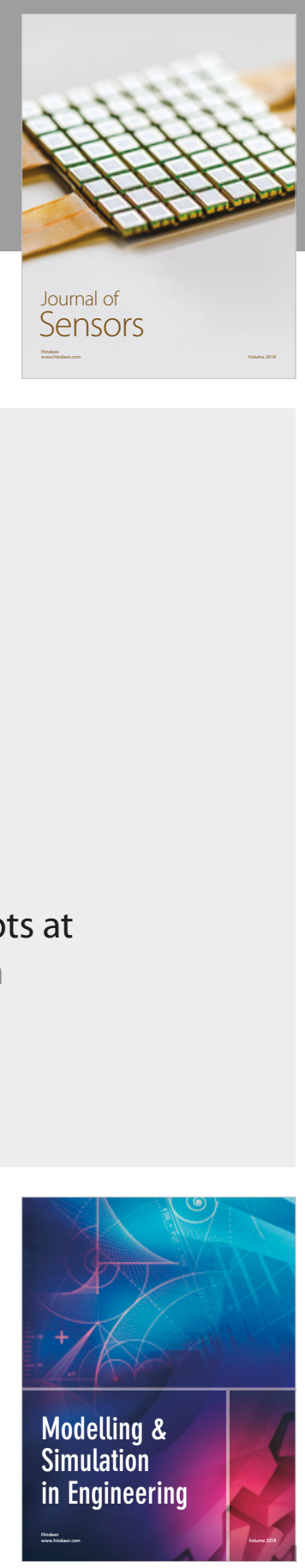

\section{Advances \\ Multimedia}
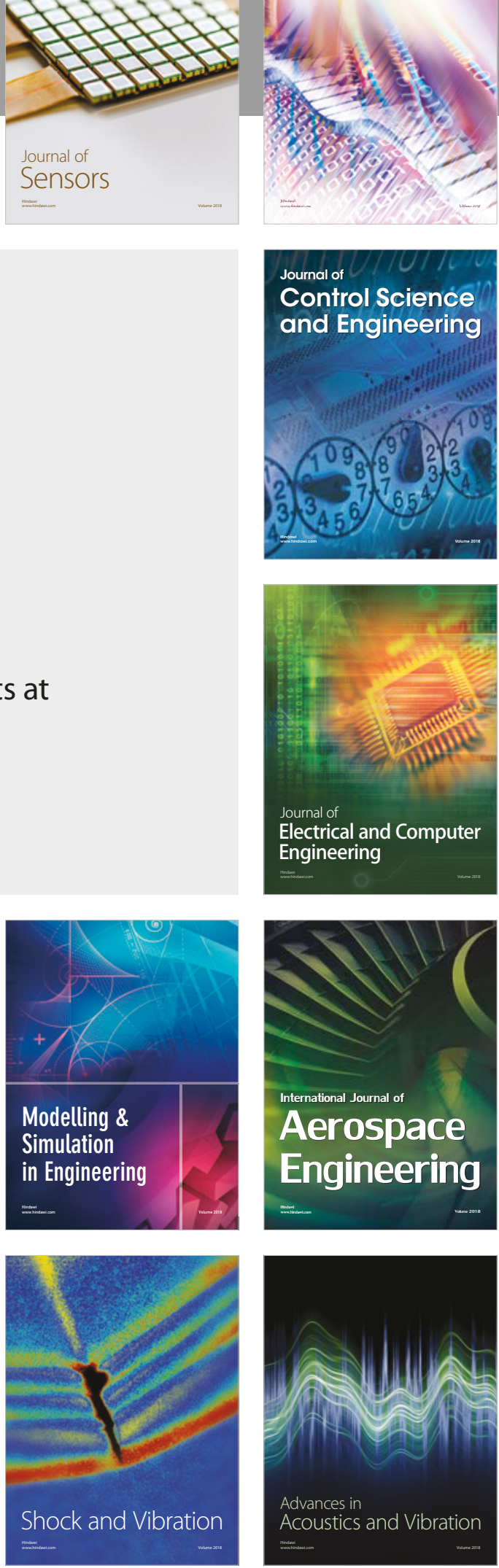